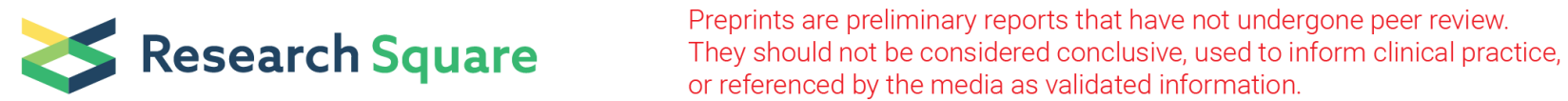

\section{Effects of temperature on interfacial evolution and mechanical properties of pure titanium and carbon steel sheets bonded via new multi-pass continuous hot-roll diffusion with nickel interlayer}

Chun-Ming Jimmy Lin ( $\nabla$ clin112@asu.edu )

Heifei University of Technology

Mohsen Saboktakin Rizi

Islamic Azad University

Chia-Kai Chen

Minghsin University of Science and Technology

\section{Research Article}

Keywords: Diffusion bonding, phase reaction, Microstructure, Mechanical Properties

Posted Date: April 2nd, 2021

DOI: https://doi.org/10.21203/rs.3.rs-357340/v1

License: (c) (i) This work is licensed under a Creative Commons Attribution 4.0 International License. Read Full License

Version of Record: A version of this preprint was published at The International Journal of Advanced Manufacturing Technology on June 23rd, 2021. See the published version at https://doi.org/10.1007/s00170-021-07455-y. 


\section{Abstract}

This study performed experiments and thermodynamic calculations to elucidate the effects of diffusion temperature on interfacial evolution and mechanical properties of pure titanium and carbon steel (i.e., steel) sheets bonded via a new type of multi-pass continuous hot-roll diffusion with nickel interlayer. The interfacial evolution results revealed that this new type of multi-pass continuous hot-roll diffusion treatment showed a very good adherence due to its metallurgy bonding, because it made a remarked improve to between compound and intermetallic compounds relationship. Secondly, in mechanical properties results revealed that the highest shear strength ( 470 MPa) was obtained at a processing temperature of $850^{\circ} \mathrm{C}$. The highest peel strength $(\sim 21 \mathrm{~N} / \mathrm{mm})$ was obtained in the sample processed at $900^{\circ} \mathrm{C}$. Bonding temperatures above and below these levels reduced the bond strength respectively due to poor atom diffusion and excessive compound formation, resulting in joint failure at the Ti-Ni interface. Extensive cleavage planes with various alignments were observed on the fracture surfaces in these cases. Overall, a hot-rolling temperature of $850^{\circ} \mathrm{C}$ was found to provide the optimal tradeoff between interfacial bonding strength and ductility. This work provided an economical and convenient solution for broadening the engineering application of interface between sheets of pure titanium and steel.

\section{Introduction}

The light weight, high strength-to-weight ratio, high toughness, high creep resistance, and excellent corrosion resistance of titanium $(\mathrm{Ti})$ and its alloys have led to their extensive use in the aerospace, chemical, marine, nuclear and medical industries [1, 2]. In many applications, it is necessary to bond Ti with some other metal or alloy in order to achieve the desired functional performance [3]. However, $\mathrm{Ti}$ is extremely reactive at high temperatures, and hence the bonding process represents a significant challenge since the Ti readily reacts with oxygen and / or nitrogen in the atmosphere [4, 5]. Nonetheless, bi-metallic joints containing Ti are extremely attractive due to their superior mechanical properties and potential to reduce the amount of materials needed to realize the joint; thereby reducing the cost. Many methods are available for joining Ti to steel, including welding [6-8], brazing [9-11] and soldering [12, 13]. However, these methods have several drawbacks, including a large difference in the thermal expansion coefficients of Ti and steel, respectively, which may cause significant distortion, and the rapid formation of intermetallic layers in the interfacial region [11]. The intermetallic layers typically consist of FeTi and $\mathrm{Fe}_{2} \mathrm{Ti}_{\mathrm{phases}}$; both of which have high hardness and brittleness, and therefore reduce the strength of the joint [14-16].

To improve the practical applicability of Ti-steel sheet (SS) bonded joints, it is necessary to increase their plasticity by reducing the volume fraction of intermetallic compounds (IMCs) using some form of solid state connection method, or selecting a suitable interlayer material for the $\mathrm{Ti}$ alloy and stainless steel so as to form a solid solution between them during the bonding process. The use of hot-roll diffusion bonding to form dissimilar joints has attracted significant attention in the recent literature [17-19]. Hot-roll bonding provides an effective means of joining similar or dissimilar materials without gross microscopic distortion or large dimensional tolerances [20, 21]. Furthermore, virtually no phase transformation or microstructural change occurs during the bonding process, and the inherent mechanical properties and behaviors of both metals are preserved [22]. In addition, the diffusion bonding process minimizes structural in-homogeneities due to the negligible effect of the temperature gradient, and yields significant cost and weight savings compared to traditional joining techniques [23]. Finally, the bonding time is very short, and thus the volume fraction of IMCs formed at the bonding interface is greatly reduced. Many studies have shown that the inclusion of an aluminum (Al) [24-26], copper (Cu) [28, 29], nickel (Ni) [22], or silver (Ag) [23] interlayer increases the strength of hot-roll diffusion-bonded Fe-Ti joints [17-19, 30] and suppresses the formation of IMCs [29-34]. However, even though a small improvement in the bonding strength is achieved, the bonding strength at the joints is 
still limited by the formation of brittle IMCs at either the Ti/interlayer or the interlayer/SS interface. Thus, it is essential to eliminate, or at least suppress, the formation of these IMCs. In this regard, Ni is one of the most effective intermediate materials for the diffusion bonding of Ti-SS since, according to the $\mathrm{Ni}-\mathrm{Fe}$ and $\mathrm{Ni}-\mathrm{Cr}$ binary phase diagrams, Ni does not form IMCs with any of the main elements of SS [35]. In addition, even though $\mathrm{TiNi}^{-\mathrm{TiNi}} 2$ and $\mathrm{TiNi}^{-} \mathrm{TiNi}_{3}$ compounds may be formed at the Ti-Ni interface, previous studies $[36,37]$ have shown that these phases are not as brittle as many other Ti-based intermetallic phases. Moreover, they coexist within the matrix (microstructure or interface), and have good toughness, thereby improving the bonding strength.

Hot rolling is an effective means of fabricating metallic composite sheets consisting of pure titanium and carbon steel with a nickel interlayer. Many studies have shown that hot rolling has the advantages of high efficiency, a low cost and an improved product quality due to its effects in improving the distribution of the intermediate material, increasing the relative density, and refining the grains and precipitates $[4,6,7,38]$. However, if the volume fraction of the intermediate material is too high (i.e., hard brittle metals), the edge of the composite rolled sheet may be cracked $[39,40]$. Therefore, hot rolling is more suitable for the processing of low volume fraction intermediate materials (i.e., ductile metals). Nonetheless, the combination of hot-rolling and diffusion bonding enables the fabrication of metallic composite sheets consisting of Ti-SS and a nickel interlayer with an excellent bonding strength.

As described above, the bonding strength of Ti-SS composite sheets can be improved by the introduction of two or more reinforcing phases. However, the interfacial strength of such tri-metal systems (i.e., the tri-metal composite sheet) is heavily dependent on their microstructural evolution during the bonding process. The evolution process is dependent in turn on the temperature at which rolling is performed. Therefore, it is essential to confirm the quantitative relationships among the diffusion-controlled reaction, the rolling temperature, and the hot deformation behavior of the constituent materials in the hot-rolling process. However, the literature provides relatively little information pertaining to the effects of processing temperature on the microstructure and mechanical properties of hot-roll diffusion-bonded joints fabricated using interlayers. This study performed experiments and thermodynamic calculations to elucidate the effects of diffusion temperature on microstructural evolution at the interfaces, including phase transformation, the growth of the diffusion layers, and the sequence of compound formation. Thermodynamic calculations focused on the Gibbs free energy and interface energy to predict the sequential phase formation at the interfaces. In the current study, we investigated the microstructural evolution and metallurgical reactions that occurred in joining $\mathrm{Ti}$ and carbon steel (i.e., steel) via hot-roll diffusion bonding with a nickel interlayer at temperatures of 800,850 , and $900^{\circ} \mathrm{C}$, respectively. Our findings related to the influence of diffusion temperature on interface evolution provide important theoretical insights and practical guidance for the development of components in medical devices, actuators, and gas turbine engines.

\section{Experimental Procedure \\ 2.1. Base metal}

The hot-roll diffusion-bonding trials were performed using pure Ti and carbon steel plates (All Metal Sales Inc. Cleveland, $\mathrm{OH}$ ) with dimensions of $150 \mathrm{~mm} \times 100 \mathrm{~mm} \times 2 \mathrm{~mm}$. The chemical compositions of the two plates were as follows: 0.08C-0.120-0.013H-0.05N-0.15Si-bal Ti (wt\%) and 0.12C-0.50Mn-0.38Si-0.034P-0.035S-bal Fe (wt\%), respectively. In fabricating the joints, the polished surfaces of the two plates were separated by an interlayer of pure $\mathrm{Ni}$ foil (purity > 99.95 at.\%) was as follows: 0.01C-0.001Sn-0.00180-0.0005Mn-0.01Si-0.001Cr-0.001Fe-0.01Si0.015Ti-0.0005Co-0.0015V-bal Ni (at.\%) with the thickness of $800 \sim 850 \mu \mathrm{m}$ and the surface roughness Ra of 0.036 $\mu \mathrm{m}$. 


\subsection{Hot-roll diffusion-bonding process}

Prior to bonding, the Ti and carbon steel plates were cleaned using emery paper and then respectively scratchbrushed using circumferential brushes of pure Ti and carbon steel (i.e., steel) to remove the oxidization layers. The edges of the two plates were then mechanically cleaned using abrasive paper. Finally, the plates were placed in an acetone-containing vessel to undergo degreasing under ultrasonic agitation for 20 minutes. Test specimens were assembled by inserting $\mathrm{Ni}$ foil between the two plates. The specimens were then placed in a furnace at $450^{\circ} \mathrm{C}$ for 600 $\mathrm{s}$ (preheating), before they underwent hot rolling using a rolling mill to form sheets of the tri-metal composite (i.e., TiNi-steel). Specifically, the sheets were fixed in place under $3 \sim 5 \mathrm{MPa}$ uniaxial load (applied along the longitudinal direction of the specimens), whereupon roll-bonding was multi-pass continuous hot rolling process with the aim of reducing the thickness of the sheets respectively by $5 \%, 15 \%, 25 \%, 30 \%$, and $45 \%$ (from an initial thickness of 16.2 $\mathrm{mm}$ to a final thickness of $11.34 \mathrm{~mm}$ ). Note that the tri-metal composite sheets underwent annealing at $400^{\circ} \mathrm{C}$ for 5 min between passes, each of which was performed at rolling speed of $0.2 \mathrm{~m} / \mathrm{s}$. Annealing was meant to remove work hardening caused by the rolling process and improve deformability in order to prevent severe edge cracking. Note also that three sets of samples were fabricated at rolling temperatures of $800^{\circ} \mathrm{C}, 850^{\circ} \mathrm{C}$, or $950^{\circ} \mathrm{C}$ under an inert atmosphere (high-purity argon gas; $99.99 \%$ ) to inhibit oxidation. Rolling was performed using 100 -mm rollers with a maximum capacity of 20 tons (see Fig. 1) and the roll-mills were lubricated using industrial oil. After the final rolling, the specimens were left in the furnace to cool naturally to room temperature and then annealed at $550^{\circ} \mathrm{C}$ in a muffle furnace for $3 \mathrm{hr}$ in an inert atmosphere (high-purity nitrogen gas; 99.999\%).

\subsection{Microstructural characterization}

Following the bonding trials, the samples were sectioned using an abrasive cutting tool to form specimens with a size of $20 \mathrm{~mm} \times 13.75 \mathrm{~mm} \times 3.15 \mathrm{~mm}$. The specimens were etched using $3 \%$ Nital solution and Kroll's solution (92 ml $\mathrm{H}_{2} \mathrm{O}+2 \mathrm{ml} \mathrm{HF}+6 \mathrm{ml} \mathrm{HCl}$ ) for $45 \mathrm{~s}$ to reveal the cross-sectional microstructure. The interfacial regions of the joint were analyzed using an optical microscope (OM, Olympus GX-51) and scanning electron microscope (SEM, JEOL JSM-5410). In addition, the chemical compositions and element distributions were examined using energy dispersive X-ray spectrometry (EDS). Finally, the phase structures of the IMCs were identified by X-ray diffraction (XRD, Rigaku, Japan) using Cu $\mathrm{K}_{\mathrm{a}}$ radiation with an operating voltage and current of $30 \mathrm{kV}$ and $20 \mathrm{~mA}$, respectively.

\subsection{Mechanical properties}

\subsubsection{Shear strength tests}

Shear tests were performed in accordance with the ASTM-D 1002-10 standard [41] (see Fig. 2(a)) using a Universal Testing Machine (UTM; Santan STM-50) with a $5 \mathrm{kN}$ load cell. The tests were performed at room temperature using a cross-head speed of $0.1 \mathrm{~mm} / \mathrm{min}$. The bond strength was calculated as the load at fracture $(\mathrm{N})$ divided by the interfacial area of the joint $\left(\mathrm{mm}^{2}\right)$ and was recorded in megapascals (MPa). For each specimen, the shear strength was reported as the average value obtained over five separate tests. The fracture surfaces of the tested samples were examined by SEM and XRD.

\subsubsection{Peel strength tests}

In accordance with the ASTM-D 1876-01 standard [42] peeling test (see Fig. 2(b)) specimens with gauge dimensions of $25 \mathrm{~mm}$ (width) by $100 \mathrm{~mm}$ (length) were machined from the bonded specimens in a direction vertical to the Ni interlayer. Tensile tests were performed at room temperature using a UTM (Hounsfield H5OKS) with a constant force 
of $50 \mathrm{~kg}$ and a crosshead speed of $20 \mathrm{~mm} / \mathrm{min}$. After each test, the break-off force was plotted against the peeling distance. The average peel strength was then evaluated as

Average peel strength $=$ average load/bond width $(\mathrm{N} / \mathrm{mm})$

For each specimen, the peel strength was reported as the average value obtained over five separate tests.

\section{Results And Discussion}

\subsection{Interfacial microstructural evolution}

For diffusion bonded joints such as those prepared in the present study, the interfacial microstructure, diffusion layer thickness, and phase composition of the reaction zone are all critically dependent on the bonding temperature. Figures 3(a) 3(c) present SEM cross-sectional images of the Ti-Ni-steel samples diffusion bonded at temperatures of 800,850 and $900^{\circ} \mathrm{C}$, respectively. For all three samples, the diffusion interface between the carbon steel plate and the $\mathrm{Ni}$ interlayer shows some defects, discontinuities, and voids. In the sample diffusion bonded at $800^{\circ} \mathrm{C}$, the interfacial region between the Ti plate and the Ni interlayer also shows obvious defects (discontinuities and voids). However, these defects are less evident in the samples processed at higher temperatures of 850 and $900^{\circ} \mathrm{C}$, respectively. In addition, the Table 1 shows the thicknesses of the NiTi and remnant NiTi layers of the bonded joints formed at different temperatures. It is seen that the thickness of the NiTi layer increases with an increasing temperature. The SEM images (see. Figures 3) confirm that a higher holding diffusion temperature increases the diffusion layer thickness. This finding is reasonable, since the use of a Ni interlayer harmonizes the rolling amount, rolling temperature, and consequently increases the strain value of the Ti-Ni diffusion interface. Note that the application of roll-bonding only once seldom results in a perfect bond without fractures or defects. This can be attributed primarily to the large amount of stress produced when the materials are subjected to the initial compression of the rollers. We therefore performed rolling multiple times at various bonding temperatures to reduce stress. This also helped to increase the dislocation density and stored energy in the Ni interlayer [43] as well as increase the thickness of the diffusion layer at the Ti-Ni interface. Moreover, according to the dislocation hypothesis $[43,44]$, dislocations at free surfaces undergoing plastic deformation break the oxide layers and produce stairs at the atomic scale, which increase the involvement of the diffusion bonded joint parts. The phenomena are discussed later in relation to the microstructural observations.

Table 1

Thicknesses of $\mathrm{NiTi}$ and remnant NiTi layers in samples processed at temperatures of 800,850 and $900^{\circ} \mathrm{C}$.

\begin{tabular}{|c|c|c|c|c|c|c|c|c|}
\hline & & & & & & & \multicolumn{2}{|c|}{ Unit: $\mu \mathrm{m}$} \\
\hline $800^{\circ} \mathrm{C}$ & & \multicolumn{2}{|c|}{$850^{\circ} \mathrm{C}$} & & \multicolumn{2}{|c|}{$900^{\circ} \mathrm{C}$} & & \\
\hline \multicolumn{2}{|l|}{ NiTi } & 5.8 & \multicolumn{2}{|l|}{ NiTi } & 12.2 & \multicolumn{2}{|l|}{ NiTi } & 29.1 \\
\hline \multirow{2}{*}{$\begin{array}{l}\text { Remnant } \\
\text { NiTi } \\
\text { layers }\end{array}$} & $\mathrm{Ni}_{3} \mathrm{Ti}$ & 5.6 & \multirow{2}{*}{$\begin{array}{l}\text { Remnant } \\
\text { NiTi } \\
\text { layers }\end{array}$} & $\mathrm{Ni}_{3} \mathrm{Ti}$ & 6.3 & \multirow{2}{*}{$\begin{array}{l}\text { Remnant } \\
\text { NiTi } \\
\text { layers }\end{array}$} & $\mathrm{Ni}_{3} \mathrm{Ti}$ & 8.4 \\
\hline & $\mathrm{NiTi}_{2}$ & 3.5 & & $\mathrm{NiTi}_{2}$ & 5.8 & & $\mathrm{NiTi}_{2}$ & 6.8 \\
\hline
\end{tabular}

As shown in Fig. 3, all three of the samples displayed compound layers (i.e., phases) at the interface between the carbon steel plate and the $\mathrm{Ni}$ interlayer. Microstructural analysis of these specimens revealed that the $\mathrm{Ni} / \mathrm{Ti} / \mathrm{steel}$ interfaces were well-differentiated. Table 2 lists the EDS analysis results showing the atomic percentages of Ti and $\mathrm{Ni}$ 
in the various diffusion specimens bonded at temperatures of 800,850 , and $900^{\circ} \mathrm{C}$. In other words, only limited element diffusion occurs at the $\mathrm{Ni}$ - Ni-steel interface, even at the highest temperature of $900^{\circ} \mathrm{C}$. However, the compound layers are apparent in the interfacial region between the Ti plate and the Ni interlayer in every case. At a lower bonding temperature $\left(800^{\circ} \mathrm{C}\right.$, Fig. $\left.3(\mathrm{a})\right)$, the compound layers have the form of isolated phases and are present in only relatively small amounts. However, as the bonding temperature increases, the number of compound layers also increases, and discrete reaction layers are formed (see Figs. 3(b) and 3(c)). In particular, on the basis of the difference in contrast, the pure $\mathrm{Ti}-\mathrm{Ni}$ interlayer interface region contains a $\mathrm{NiTi}_{2}$ compound layer (i.e., dark-gray region) next to the Ti plate and a $\mathrm{Ni}_{3} \mathrm{Ti}$ compound layer (i.e., gray- white region) adjacent to the $\mathrm{Ni}$ interlayer. The two compound layers are separated by a NiTi compound layer (i.e., gray region) (see Fig. 3(c), for example). According to $[45,46]$, the formation process for the $\mathrm{Ni}_{3} \mathrm{Ti}$, $\mathrm{NiTi}$, and $\mathrm{NiTi}_{2}$ phases can be elaborated as follows. Under the effects of the elevated bonding temperature, a $\mathrm{Ni}_{3} \mathrm{Ti}$ compound layer is rapidly formed during the initial stage of the bonding process due to the relatively low diffusion speeds of $\mathrm{Ti}$ and $\mathrm{Ni}$, respectively.

Table 2

EDS analysis results for chemical compositions (at\%) of compound layers formed in pure Ti and carbon steel hot-roll diffusion bonded joints with Ni interlayer processed at different temperatures.

\begin{tabular}{|c|c|c|c|c|c|c|c|c|c|c|c|}
\hline & & \multicolumn{2}{|c|}{ Unit: at\% } & & \multicolumn{3}{|c|}{ Unit: at\% } & & & \multicolumn{2}{|c|}{ Unit: at\% } \\
\hline & & $\mathrm{Ni}$ & $\mathrm{Ti}$ & & & $\mathrm{Ni}$ & $\mathrm{Ti}$ & & & $\mathrm{Ni}$ & $\mathrm{Ti}$ \\
\hline \multirow[t]{3}{*}{$800^{\circ} \mathrm{C}$} & NiTi & 49 & 51 & \multirow[t]{3}{*}{$850^{\circ} \mathrm{C}$} & NiTi & 49 & 51 & \multirow[t]{3}{*}{$900^{\circ} \mathrm{C}$} & NiTi & 51 & 49 \\
\hline & $\mathrm{Ni}_{3} \mathrm{Ti}$ & 76 & 24 & & $\mathrm{Ni}_{3} \mathrm{Ti}$ & 76 & 24 & & $\mathrm{Ni}_{3} \mathrm{Ti}$ & 74 & 26 \\
\hline & $\mathrm{NiTi}_{2}$ & 33 & 67 & & $\mathrm{NiTi}_{2}$ & 33 & 67 & & $\mathrm{NiTi}_{2}$ & 32 & 68 \\
\hline
\end{tabular}

The strong affinity of Ti-Ni atom pairs (i.e., the high negative mixing enthalpy of the principal elements in the alloy system) caused the $\mathrm{Ni}$ atoms to diffuse quickly into the $\mathrm{Ti}$ (i.e., $\beta-\mathrm{Ti})\left(\mathrm{D}=3 \times 10^{-12} \mathrm{~m}^{2} \mathrm{~s}^{-1}\right.$ at $\left.900^{\circ} \mathrm{C}\right)$ [47]. Isothermal transformation under the effects of $\mathrm{Ni}$ atom diffusion led to the formation of $\beta$-Ti phase in accordance with the Ti-Ni binary phase diagram [48]. As the holding time increased, the inward diffusion of Ni atoms also increased. The a-Ti phase transformed into $\mathrm{NiTi}_{2}$ through an isothermal reaction of $\beta-\mathrm{Ti} \rightarrow \mathrm{NiTi}_{2}$, due to similarities in the crystal structure and composition of $\mathrm{NiTi}$ and $\mathrm{NiTi}_{2}$. The $\beta$-Ti phase and disordered a-Ti phase dissolve a greater amount of $\mathrm{Ni}$ than the ordered $\mathrm{NiTi}_{2}$ compound. As a result, excess dissolved $\mathrm{Ni}$ is expelled from the $\mathrm{NiTi}_{2}$ phase. The segregated $\mathrm{Ni}$ atoms combined with the $\mathrm{Ni}$ atoms diffused from the Ti substrate to form $\mathrm{Ni}_{3} \mathrm{Ti}^{\mathrm{NiTi}} \mathrm{Ni}_{2}$ with almost no $\mathrm{Ni}$ continuously formed adjacent to the $\mathrm{Ni}_{3} \mathrm{Ti}$ compound, likely due to the diffusion of $\mathrm{Ti}$ atoms toward the $\mathrm{NiTi}$ at high temperatures. This balanced the diffusion of $\mathrm{Ni}$ in the opposite direction, which limited the formation of $\mathrm{NiTi}_{2}$. The shorter diffusion distance of Ti should be limited to multi-layers with a short period, as shown in Table 1 . The chemical affinity of $\mathrm{Ni}_{3} \mathrm{Ti}$ phase is greater than that of $\mathrm{NiTi}_{2}$ phase, manifesting as a difference in chemical potential. Consequently, $\mathrm{NiTi}_{2}$ compound precipitates are formed in the a-Ti matrix in accordance with the eutectoid reaction $\beta$ $\mathrm{Ti} \rightarrow \mathrm{a}-\mathrm{Ti}+\mathrm{NiTi}_{2}$ during the cooling process $[48,49]$. A close inspection of Figs. $3(\mathrm{~b})$ and (c) reveals the presence of $\mathrm{a}-$ Ti phase $+\beta$-Ti phase in the form of discrete needle-shaped particles in the matrix of the $\mathrm{Ni}_{3} \mathrm{Ti}$ compound and $\beta-\mathrm{Ti}$ phases in the form of discrete islands in the matrix of the $\mathrm{NiTi}_{2}$ phase in the compound reaction layers. This can be attributed to the high negative mixing enthalpy of $\mathrm{Ni}-\mathrm{Ti}$, which led to the formation and subsequent segregation of 
atom pairs within the matrix (NiTi: $-40 \mathrm{~kJ} / \mathrm{mol} \mathrm{NiTi}_{2}:-33 \mathrm{~kJ} / \mathrm{mol}$, and $\mathrm{Ni}_{3} \mathrm{Ti}:-53 \mathrm{~kJ} / \mathrm{mol}$ ) [50-52]. Under these conditions, the probability of compound formation was as follows: $\mathrm{Ni}_{3} \mathrm{Ti}_{\rightarrow} \rightarrow \mathrm{NiTi}_{2} \rightarrow \mathrm{NiTi}$.

In $\mathrm{NiTi}, \mathrm{NiTi}_{2}$ and $\mathrm{Ni}_{3} \mathrm{Ti}$ compounds form as a result of inter-diffusion of the $\mathrm{Ti}$ and $\mathrm{Ni}$ elements during the bonding process. The associated chemical reaction equation can be stated as follows:

$\mathrm{Ni}+\mathrm{Ti}(\mathrm{s})=\mathrm{NiTi}$

$\mathrm{Ni}(\mathrm{s})+2 \mathrm{Ti}(\mathrm{s})=\mathrm{NiTi}_{2}$

$3 \mathrm{Ni}(\mathrm{s})+\mathrm{Ti}(\mathrm{s})=\mathrm{Ni}_{3} \mathrm{Ti}$

$\mathrm{TiNi}+\mathrm{Ti}(\mathrm{s})=\mathrm{NiTi}_{2}$

$\mathrm{TiNi}+2 \mathrm{Ni}(\mathrm{s})=\mathrm{Ni}_{3} \mathrm{Ti}$

$\mathrm{NiTi}_{2}+\mathrm{Ni}(\mathrm{s})=\mathrm{NiTi}_{2}$

$\mathrm{Ni}_{3} \mathrm{Ti}+2 \mathrm{Ti}(\mathrm{s})=\mathrm{Ni}_{3} \mathrm{Ti}$

$\mathrm{NiTi}_{2}+3 \mathrm{Ni}(\mathrm{s})=\mathrm{NiTi}+\mathrm{Ni}_{3} \mathrm{Ti}$

$\mathrm{Ni}_{3} \mathrm{Ti}+3 \mathrm{Ti}(\mathrm{s})=\mathrm{NiTi}_{2}+\mathrm{NiTi}$

Based on the Table of Thermodynamic Properties in [53], we calculated the change in Gibbs free energy $(\Delta G)$ involved in the various reactions at the Ti-Ni diffusion interface under various temperatures. As shown in Table 3, we then estimated the likelihood of each reaction occurring based on the $\Delta$ Grelated to the formation of the compound phases described in reaction Eqs. (1) (9).

Table 3

Temperature dependence of standard Gibbs free energy in reactions occurring at Ti-Ni diffusion interface at various temperatures [54].

\begin{tabular}{|llllllllll|}
\hline$\Delta \mathbf{G}$ & $\mathbf{1}$ & $\mathbf{2}$ & $\mathbf{3}$ & $\mathbf{4}$ & $\mathbf{5}$ & $\mathbf{6}$ & $\mathbf{7}$ & $\mathbf{8}$ & $\mathbf{9}$ \\
\hline $550^{\circ} \mathrm{C}$ & -14.140 & -17.355 & -35.975 & -3.214 & -21.835 & -10.926 & -6.446 & -32.761 & -9.661 \\
\hline $600^{\circ} \mathrm{C}$ & -14.001 & -17.125 & -35.031 & -3.183 & -21.246 & -10.837 & -5.621 & -31.123 & -9.435 \\
\hline $650^{\circ} \mathrm{C}$ & -13.804 & -16.963 & -36.172 & -3.159 & -22.368 & -10.645 & -5.240 & -33.013 & -8.398 \\
\hline $700^{\circ} \mathrm{C}$ & -13.661 & -16.794 & -36.250 & -3.133 & -22.588 & -10.529 & -4.735 & -33.117 & -7.867 \\
\hline $750^{\circ} \mathrm{C}$ & -13.517 & -16.622 & -36.324 & -3.105 & -22.807 & -10.412 & -4.227 & -33.219 & -7.332 \\
\hline $800^{\circ} \mathrm{C}$ & -13.324 & -16.465 & -36.863 & -3.012 & -23.023 & -10.772 & -3.362 & -34.351 & -6.993 \\
\hline $850^{\circ} \mathrm{C}$ & -13.061 & -16.232 & -37.154 & -2.962 & -23.452 & -10.541 & -3.320 & -34.415 & -6.521 \\
\hline $900^{\circ} \mathrm{C}$ & -12.865 & -15.821 & -37.834 & -2.953 & -23.932 & -10.332 & -3.246 & -34.861 & -6.21 \\
\hline
\end{tabular}


Figure 4 shows the $\Delta \mathrm{G}$ as a function of temperature in the nine reaction processes described above. $\Delta \mathrm{G}$ was less than zero in all three of the reactions over a temperature range of $550-900^{\circ} \mathrm{C}$ (i.e.,773 $\mathrm{K}-1173 \mathrm{~K}$ ). The second law of thermodynamics stipulates that the probability of a compound forming via spontaneous reaction is closely related to its $\Delta \mathrm{G}$ [54]. Thus, $\Delta \mathrm{G}$ also determines the sequence of compound formation in any given reaction. Figure 4 and Table 3 illustrate the fluctuations in $\Delta \mathrm{G}$ as a function of temperature in all of the reactions that occurred at the Ti/ $\mathrm{Ni}$ interface. Note that all of the compounds associated with $\mathrm{Ni}_{3} \mathrm{Ti}_{1} \mathrm{NiTi}_{2}$, and $\mathrm{NiTi}$ formed within a temperature range of $550-770^{\circ} \mathrm{C}$ (i.e.,773 K-1043K) [54, 55]. From this, we can infer that the $\mathrm{Ni}_{3} \mathrm{Ti}$ compound (reaction 3 (i.e., $\mathrm{R}(3)$ ) has a lower $\Delta \mathrm{G}$ (more negative) than those of $\mathrm{NiTi}(\mathrm{R}(1))$ and $\mathrm{NiTi}_{2}(\mathrm{R}(2))$. Based on the principle of minimum energy, $\mathrm{Ni}_{3} \mathrm{Ti}$ forms before $\mathrm{NiTi}_{2}$ and $\mathrm{NiTi}$. Thus, from the perspective of $\Delta \mathrm{G}$ only (i.e., disregarding the impact of all other factors), we derive the following sequence for the formation of Ti-Ni compounds: $\mathrm{Ni}_{3} \mathrm{Ti}>\mathrm{NiTi}_{2}>\mathrm{NiTi}$. Our inference that the $\mathrm{Ni}_{3} \mathrm{Ti}$ compound preferentially formed at the Ti/Ni interface during the diffusion-bonding process implies that phase formation was also related to molecular kinetics under non-equilibrium conditions. As shown in Table 3 , the $\Delta G$ in $\mathrm{R}(3)$ decreased (i.e., became more negative) with an increase in temperature, whereas the $\Delta \mathrm{G}$ in $\mathrm{R}(1)$ and $\mathrm{R}(2)$ increased. We can see in Fig. 4 that in the second diffusion stage at $800-900^{\circ} \mathrm{C}$ (i.e.,1073 K-1173 K), R(5) and R(8) took precedence over all other reactions except $\mathrm{R}(1), \mathrm{R}(2)$, and $\mathrm{R}(3)$, resulting in a rapid increase in the amount of $\mathrm{Ni}_{3} \mathrm{Ti}$ compound. Subsequent long-range atomic diffusion initiated other reactions, such as the reaction of $\mathrm{Ni}_{3} \mathrm{Ti}_{\mathrm{i}}$ with $\mathrm{Ti}$ to form stable compounds of $\mathrm{NiTi}$ and $\mathrm{NiTi}_{2}$. Eventually, all of the pure $\mathrm{Ti}, \mathrm{Ni}$, and $\mathrm{Ni}_{3} \mathrm{Ti}$ were consumed. Note that the $\mathrm{Ni}_{3} \mathrm{Ti}$ and $\mathrm{NiTi}_{2}$ compounds formed before $\mathrm{NiTi}$, due to their higher $\Delta \mathrm{G}$ (i.e., more negative) and less pronounced increase in surface energy [55]. We were unable to determine the sequences of $\mathrm{Ni}_{3} \mathrm{Ti}_{\text {and }} \mathrm{NiTi}_{2}$ formation, due to similar surface energy values [56].

It is noted that this inference is consistent with that of previous studies [57-62], which also reported the preferential formation of $\mathrm{Ni}_{3} \mathrm{Ti}$ compound. The formation of a high-volume fraction of $\mathrm{NiTi}_{2}$ compound implies that a large quantity of $\mathrm{Ni}$ is depleted during the diffusion bonding process. Therefore, the capabilities of the different diffusion temperatures in dissolving the $\mathrm{NiTi}_{2}$ compound are limited, if the fundamental mechanism accounting for the severe $\mathrm{Ni}$ loss is not uncovered. However, the serious loss of $\mathrm{Ti}$ content in the diffusion process implies that it is impossible to attain a full NiTi compound. In addition, some irregular-shaped voids can be seen in Figs. 3(a) (c) arising from the higher diffusion coefficient of Ni compared to that of $\mathrm{Ti}$, which results in an imbalance in the mass flow across the interface. The volume fraction of these voids reduces with an increasing bonding temperature, which suggests that a higher temperature enhances the thermal excitation of the atoms and hence facilitates an improved inter-diffusion and reaction process across the interface [63-68]. It is noted that the present observations are consistent with those of previous studies for diffusion couples of Ti-Ni and microduplex stainless steel-Ti alloy processed at temperatures in the range of $700 \sim 850^{\circ} \mathrm{C}$, respectively $[68,69]$.

It is also important to consider the atomic ratio of $\mathrm{Ti}$ and $\mathrm{Ni}$ when seeking to elucidate the formation of $\mathrm{Ni}_{3} \mathrm{Ti}^{\mathrm{N}} \mathrm{NiTi}$ and $\mathrm{NiTi}_{2}$ compounds at the Ti-Ni diffusion interface at various temperatures. Including the Gibbs free energy of mixing $\left(\Delta \mathrm{G}_{\mathrm{mix}}\right)$ in the binary (transition) metal-metal system helped to explain why homogeneous NiTi formed when the atomic ratio of $\mathrm{Ni}$ to $\mathrm{Ti}$ was $1: 1 . \Delta \mathrm{G}_{\mathrm{mix}}$ refers to changes in the energy of the system under the effects of diffusion [70]. Diffusion for a sufficient duration permits the formation of mixed phases $B_{1}{ }_{x} A_{x}$ at the interface of the two original phases $A(\mathrm{Ti})$ and $B(\mathrm{Ni})$, where variable $x$ indicates the atomic percentage of the corresponding element. Note that $\Delta \mathrm{G}_{\mathrm{mix}}$ is a function of $x$ and temperature of $\mathrm{T}$. Mixing enthalpy can be estimated using the method outlined in [71] and is taken as configurational entropy. Thus, $\Delta G_{\text {mix }}$ can be calculated as follows [70, 72]:

$$
\Delta G_{\mathrm{mix}}(X, T)=\mathrm{x} F_{\mathrm{B}}^{\mathrm{A}}(x) \Delta H_{\mathrm{AinB}}^{\text {interface }}-T \Delta S_{\mathrm{Conf}}
$$


where $\Delta H_{\mathrm{AinB}}^{\text {interface }}$ indicates the change in enthalpy resulting from the dissolution of $1 \mathrm{M}$ of $\mathrm{A}$ in $\mathrm{B}$ and $\Delta S_{\mathrm{conf}}$ indicates the change in configurational entropy. $F_{\mathrm{B}}^{\mathrm{A}}(x)$ is the degree to which $\mathrm{A}$ atoms are surrounded by $\mathrm{B}$ atoms, which can be accurately estimated as follows [70]

$$
F_{\mathrm{B}}^{\mathrm{A}}(x)=C_{\mathrm{B}}^{\mathrm{S}}(x)=\frac{(1-x) V^{\frac{2}{\overline{\mathrm{B}}}}}{V^{\frac{2}{\overline{\mathrm{A}}}}+(1-x)^{\frac{2}{\overline{\mathrm{B}}}}}
$$

where $C_{\mathrm{B}}^{\mathrm{S}}(x)$ indicates the volume fraction of B. $V_{\mathrm{A}}$ and $V_{\mathrm{B}}$ refer to the molar volumes of pure crystalline solids (i.e., $\left.V_{\mathrm{Ti}}=10.6 \mathrm{~cm}^{3} / \mathrm{mol}, V_{\mathrm{Ni}}=6.5 \mathrm{~cm}^{3} / \mathrm{mol}[73,74]\right)$.

The $\Delta H_{\text {AinB }}^{\text {interface }}$ and $\Delta S_{\text {conf }}$ in the binary crystal system are defined as follows $[73,75]$ :

$$
\Delta H_{\text {AinB }}^{\text {interface }}=\frac{2 p f_{\mathrm{A}} V_{\bar{\AA}}^{\frac{2}{\bar{R}}}}{n^{\frac{1}{\beta}}+n n_{\mathrm{B}}^{\frac{1}{3}}}\left[-\left(\Phi_{\mathrm{A}}^{*}-\Phi_{\mathrm{B}}^{*}\right)^{2}-\frac{R}{P}\right]
$$

3

$$
\Delta S_{\mathrm{Conf}}=-R[x \ln (x)+(1 f x) \ln 1(11 x)]
$$

4

where $n_{\mathrm{A}}$ and $n_{\mathrm{B}}$ are the electron density parameters (i.e., $n^{\frac{1}{\hat{\mathrm{A}}}}=1.47, n_{\mathrm{B}}^{\frac{1}{3}}=1.75$ ) [73] used to describe phenomena occurring at an interface at the atomic scale. Parameters $\Phi_{\mathrm{A}}^{*}$ and $\Phi_{\mathrm{B}}^{*}$ are used to describe ionic bonds in metals (i.e., $\left.\left.\Phi_{A}^{*}=3.65, \Phi_{B}^{*}=5.20\right)[73,74]\right) . Q, R$, and $P$ are constants with the following values: $Q / R(9.4), R / P(1.9)$, and $P$ (12.35).

The above equations were used to calculate $\Delta G_{\text {mix }}$ and the results are shown in Fig. 5 in terms of variations in $\Delta G_{\text {mix }}$ as a function of the atom percentage of $\mathrm{Ti}$ in $\mathrm{Ni}_{1-x} \mathrm{Ti}_{x}$. We can see that when the atom percentage of $\mathrm{Ti}$ was fixed, there was a decrease in the $\Delta \mathrm{G}_{\mathrm{mix}}$ of Ti-Ni diffusion with an increase in temperature. When $\mathrm{x}$ was increased from 0.2 to 0.7 , the value of $\Delta \mathrm{G}_{\mathrm{mix}}$ first decreased and then increased. The lowest $\Delta \mathrm{G}_{\mathrm{mix}}$ value was obtained when the value of $x$ was roughly 0.5 , which indicates the point at which NiTi formation occurred (0.48-0.51). However, the formation of $\mathrm{Ni}_{3} \mathrm{Ti}$ and $\mathrm{NiTi}$ is easy to understand from the perspective of metallurgical characteristics or thermodynamics. We speculate that the respective $\Delta \mathrm{Gmix}$ values of $\mathrm{Ni3Ti}$ and $\mathrm{NiTi}$ during Ti-Ni diffusion decreased with an increase in temperature; i.e., moving toward dynamic thermal equilibrium. $\mathrm{Ni}_{3} \mathrm{Ti}$ generation (near the $\mathrm{Ni}$ side) was followed by $\mathrm{NiTi}_{2}$ (near the pure Ti side). This was followed by the formation of NiTi at the interface between the two. During the 
initial formation of $\mathrm{Ni}_{3} \mathrm{Ti}_{1} \mathrm{NiTi}_{2}$, and $\mathrm{NiTi}$, diffusion was still ongoing. This is particularly true of the $\mathrm{Ti}$ (rapid diffusion), which resulted in the steady growth of $\mathrm{NiTi}$. The unsteady growth of $\mathrm{NiTi}_{2}$ was the result of $\mathrm{Ti}$ diffusion toward the $\mathrm{NiTi}$ and pure $\mathrm{Ti}$ sides. Note that the $\mathrm{NiTi}_{2}$ region in phase images was extremely narrow. Nonetheless, the formation of $\mathrm{NiTi}_{2}$ cannot be used to analyze the mutual influence between $\mathrm{NiTi}_{2}$ and $\mathrm{Ni}_{3} \mathrm{Ti}_{\text {or }}$ between $\mathrm{NiTi}_{2}$ and $\mathrm{NiTi}$. Further analysis is required.

\subsection{Mechanical properties}

\subsubsection{Interfacial hot-roll diffusion-bonded joint quality 3.2.1.1 Shear strength of hot-roll diffusion-bonded joints}

The shear strength is an important index for evaluating the interfacial bonding quality of hot-roll clad composites. Figure 6 shows the interfacial shear strengths of the present hot-rolled joints processed at temperatures of $800^{\circ} \mathrm{C}$, $850^{\circ} \mathrm{C}$ and $900^{\circ} \mathrm{C}$, respectively. For a rolling temperature of $800^{\circ} \mathrm{C}$, the shear strength is equal to approximately 343 $\mathrm{MPa}$. However, the shear strength increases to a maximum value of $470 \mathrm{MPa}$ in the sample processed at a rolling temperature of $850^{\circ} \mathrm{C}$. This value is markedly higher than the values reported in previous studies [76]. This can be explained by the increase in the thickness of the NiTi layer and the fact that the $\beta$-Ti phase exists as discrete needleshaped particles in the matrix of the $\mathrm{Ni}_{3} \mathrm{Ti}$ phase, whereas a-Ti phase exist as discrete islands. The atomic migration of chemical species across the bond line increased with an increase in bonding temperature. The presence of Ni in the interfacial zone adjacent to the Ti substrate stabilized the $\beta$-Ti phase, which led to the formation of a plastic zone capable of bridging cracks and thereby maintaining the integrity of the interfacial microstructure. Furthermore, a lower bonding temperature suppressed the migration of atoms from the pure Ti substrate toward the carbon steel substrate (and vice versa). As a result, an incomplete coalescence of the mating surfaces occurs $[15,77]$. However, at higher rolling temperatures, the shear strength is significantly improved as a result of both a greater inter-diffusion of elements from the $\mathrm{Ti}$ and carbon steel substrates and the temperature-induced plastic collapse of the mating surface asperities, which results in a more intimate contact of the two surfaces and an enhanced bonding outcome as a result. Interestingly, however, the shear strength reduces to approximately $386 \mathrm{MPa}$ as the bonding temperature is further increased to $900^{\circ} \mathrm{C}$. The reduction in the shear strength implies that, at a high bonding temperature, the $\mathrm{Ni}$ interlayer fails to completely block the diffusion of carbon atoms to the Ti side. Consequently, compound phase reaction layers with a relatively large thickness are produced in the interfacial region between the Ti substrate and the $\mathrm{Ni}$ interlayer (see Fig. 3). As the rolling process proceeded, compound phase particles tended to disintegrate under the effects of embrittlement. The resulting formation of irregular micro-voids led to a significant reduction in shear strength, thereby demonstrating that shear strength depends heavily on the microstructure at the interface.

\subsubsection{Fracture morphology of hot-roll diffusion-bonded joints}

The fracture surfaces of the hot-roll diffusion-bonded joints were observed via SEM, as shown in Fig. 7. (Note that for each sample, fracture occurred at the Ti side due to the formation of compound phases.) The dark region in Fig. 7(a) confirms the presence of micro-voids due to the minimal diffusion of intermetallic elements at $800^{\circ} \mathrm{C}$. These microvoids reduce the contact area between the mating surfaces, and therefore degrade the shear strength of the joint. For the sample bonded at a higher temperature of $850^{\circ} \mathrm{C}$, a larger number of intermetallic phases are formed in the interfacial region. The facture surface shows evidence of a ductile behavior (see Fig. 7(b)), and hence it is inferred that these intermetallic phases enhance the bonding strength of the joint without any embrittlement effect. However, for the sample bonded at $900^{\circ} \mathrm{C}$ (see Fig. 7(c)), the fracture surface contains multiple cleavage planes with different alignments. In other words, the thick compound phase reaction layers impart a brittleness to the interfacial region and

Page 10/23 
cause the joint to fail accordingly. In addition, the river pattern differs from grain to grain and the size of the river patterns increases with an increasing bonding temperature.

Figure 8 shows the X-ray diffraction patterns of the three fracture surfaces in Fig. 7. For the specimen processed at $800^{\circ} \mathrm{C}$, the diffusion zone contains $\mathrm{NiTi}_{2}, \mathrm{NiTi} \mathrm{Ni}_{3} \mathrm{Ti}, \mathrm{a}-\mathrm{Ti}$ and $\beta$-Ti phases (see Fig. 8(a)). However, at $850^{\circ} \mathrm{C}$, the diffusion zone consists mainly of $\mathrm{NiTi}_{2}, \mathrm{a}-\mathrm{Ti}$ and $\beta$ - Ti (see Fig. 8(b)). Finally, for the sample processed at $900^{\circ} \mathrm{C}$, the diffusion zone consists predominantly of $\mathrm{NiTi}_{2}, \mathrm{a}-\mathrm{Ti}$ and $\beta$-Ti phases. Notably, titanium carbide (TiC) is not observed in the diffusion zones of any of the samples. Hence, it is inferred that the Ni interlayer serves as an effective barrier in preventing the diffusion of Ti atoms from the Ti plate to the carbon steel side. The SEM images in Fig. 3 show the presence of $\mathrm{a}-\mathrm{Ti}$ and $\beta$-Ti phases in the Ti-Ni interface region of all three samples. However, $\mathrm{a}-\mathrm{Ti}$ and $\beta$-Ti phases are not evident in the corresponding X-ray diffraction patterns since the bonded samples fracture through the $\mathrm{NiTi}_{2}$ and $\beta$ Ti regions, and the X-ray diffraction depth is insufficiently large to perform sub-surface detection. However, $\mathrm{NiTi}_{2}$ phase is evident in the XRD patterns of the joints processed at temperatures of $850^{\circ} \mathrm{C}$ and $900^{\circ} \mathrm{C}$, which confirms the migration of $\mathrm{Ti}$ elements from the pure Ti plate toward the carbon steel substrate at higher temperatures.

\subsubsection{Peel strength of hot-roll diffusion-bonded joints}

The interfacial bonding strength is one of the most important mechanical characteristics of clad composites. In the present study, the interfacial bonding strength was evaluated by means of ASTM-D 1876-01 standard [42]. The corresponding results are shown in Fig. 9 for both the mean peel strength of each sample (see Fig. 9(a)) and the variation of the peel strength with the peeling displacement. The samples processed at temperatures of $800^{\circ} \mathrm{C}$ and $850^{\circ} \mathrm{C}$ have peel strengths of $10 \mathrm{~N} / \mathrm{mm}$ and $18 \mathrm{~N} / \mathrm{mm}$, respectively. However, the peel strength increases to $21 \mathrm{~N} / \mathrm{mm}$ in the sample processed at $900^{\circ} \mathrm{C}$. In other words, the average peel strength increases by approximately $110 \%$ as the bonding temperature is increased from $800^{\circ} \mathrm{C}$ to $900^{\circ} \mathrm{C}$.

Several factors affect the interfacial bonding strength of hot-roll diffusion-bonded joints, including the formation of compound phases, cracking, and the extent of elemental diffusion. Intermetallics generally have a complex crystal structure and are brittle due to their ionic and covalent bonding [78]. When Intermetallics are present in the interfacial regions of joints such as those prepared in the present study, they serve as inclusions and prompt crack. Crack is followed by a region of stable crack propagation and later, fast-fracture. Furthermore, defects in the interfacial region act as stress concentrators, which increase the local stress intensity and promote crack nucleation [68]. However, as the rolling temperature increases, a greater number of atoms gain the activation energy required to undergo diffusion. Consequently, the peel strength increases, as shown in Fig. 9(a). However, a higher temperature also increases the rate of atomic diffusion of $\mathrm{Ni}$ atoms toward the pure $\mathrm{Ti}$ plate. This in turn increases the size and number of the compound phases formed in the interfacial region, which increases the local stress and prompts crack nucleation and growth. As a result, the ductility reduces, as shown in Fig. 9(b).

Overall, the present results show that the interfacial bonding ability is related to the formation and distribution of compound phases between the Ti and Ni layers in the hot-roll diffusion-bonded joints. Moreover, for the present samples, a hot-rolling temperature of $850^{\circ} \mathrm{C}$ results in the optimal tradeoff between the interfacial bonding strength and the ductility.

\section{Conclusions}

We applied a hot-roll solid-state diffusion-bonding technique to join commercially-pure Ti plates to carbon steel substrates with a Ni interlayer (i.e., the tri-metal composite) at processing temperatures of 800,850 , and $900^{\circ} \mathrm{C}$, 
respectively. The experimental results support the following conclusions:

1. Inter-diffusion between the $\mathrm{Ni}$ interlayer and pure Ti substrate resulted in the formation of layers of $\mathrm{NiTi}_{2}, \mathrm{NiTi}$, and $\mathrm{Ni}_{3} \mathrm{Ti}$ phase at the Ti-Ni interface. Note that the formation sequence of the three inter-metallic compounds was as follows: 1) $\mathrm{Ni}_{3} \mathrm{Ti}$ formed first; 2) $\mathrm{NiTi}_{2}$ formed when the $\mathrm{Ni}_{3} \mathrm{Ti}$ layer reached a certain thickness; and 3) $\mathrm{Ti}$ and $\mathrm{Ni}$ diffused into the $\mathrm{NiTi}_{2}$ and $\mathrm{Ni}_{3} \mathrm{Ti}$ layers to form $\mathrm{NiTi}$. As the thickness of the $\mathrm{NiTi}$ layer increased, a portion of the $\mathrm{Ni}_{3} \mathrm{Ti}$ layer was consumed. This can be attributed to the fact that the nucleation of $\mathrm{Ni}_{3} \mathrm{Ti}_{\text {and }} \mathrm{NiTi}_{2}$ occurred prior to that of $\mathrm{NiTi}$, due to their lower Gibbs free energy. $\beta$-Ti phases additionally exist as discrete needle-shaped particles in the matrix of the $\mathrm{Ni}_{3} \mathrm{Ti}$ phase, while $\mathrm{\alpha}$-Ti phase exist as discrete islands. The atomic migration of chemical species across the bond line increases with an increasing bonding temperature. The presence of $\mathrm{Ni}$ in the interfacial zone adjacent to the Ti substrate stabilizes the $\beta$-Ti phase, leads to the formation of a-Ti phase, and acts as a diffusion barrier which prevents the migration of Ti atoms to the carbon steel substrate. The Ni-carbon steel interface is thus free from any reaction products for the considered bonding temperatures of $800 \sim 900^{\circ} \mathrm{C}$.

2. The maximum shear strength ( $470 \mathrm{MPa})$ is obtained in the sample processed at $850^{\circ} \mathrm{C}$ due to a better coalescence of the mating surfaces and an improved diffusion of the atomic species. For a lower bonding temperature of $800^{\circ} \mathrm{C}$, the shear strength is reduced due to a more limited plastic deformation of the mating surface asperities. By contrast, for a higher bonding temperature of $900^{\circ} \mathrm{C}$, the shear strength is degraded due to the formation of brittle $\mathrm{TiNi}_{3}$ type micro-intermetallic layers.

3. The peel strength increases with an increasing bonding temperature and has a value of $21 \mathrm{~N} / \mathrm{mm}$ in the sample processed at $900^{\circ} \mathrm{C}$. The enhanced peel strength at higher temperatures can be attributed to an increase in the intermetallic compounds and a greater composition homogeneity in the diffusion zone between the pure $\mathrm{Ti}$ and carbon steel plates and $\mathrm{Ni}$ interlayer. Overall, the results suggest that the failure behavior of the joints is directly related to the formation and distribution of compound phases at the bond interface.

\section{Declarations}

\section{Acknowledgements}

The authors would like to thank the Ministry of Science and Technology of Taiwan for the financial support of this study under Contract No. MOST 105-2218-E-027-011-MY3. Finally, the authors are grateful to Mr. Mohsen Saboktakin Rizi and Mr. Chia-Kai Chen for his assistance in publishing this work.

\section{Contributions}

Author contribution All authors contributed to the research, writing, and reviewing of the paper. Professor Chun-Ming Lin analyzed the experimental results and reviewed and edited the manuscript. Mr. Mohsen Saboktakin Rizi and Mr. Chia-Kai Chen conceived the experimental design, conducted the experiments, and prepared the draft manuscript

\section{Funding}

The research is supported by the Ministry of Science and Technology of Taiwan for the financial support of this study under Contract No. MOST 105-2218-E-027-011-MY3..

\section{Data availability}

Page $12 / 23$ 
The authors confirm that the data supporting the findings of this study are available within the article. The raw data are available from the corresponding author upon a request.

\section{Declarations}

Ethical approval The work contains no libelous or unlawful statements, does not infringe on the rights of others, or contains material or instructions that might cause harm or injury. Consent to participate The authors consent to participate. Consent for publication Informed consent was obtained from all individual participants involved in the study. Conflict of interest The authors declare that they have no conflict of interest.

\section{References}

[1] F. Weng, C. Chen, H. Yu, Research status of laser cladding on titanium and its alloys: A review. Mater. Des., 58 (2014), pp. 412-425

[2] A. Karolczuk, M. Kowalski, R. Bański, F. Żok, Fatigue phenomena in explosively welded steel-titanium clad components subjected to push-pull loading. Int. J. Fatigue, 48 (2013), pp. 101-108.

[3] W.B. Lee, C.Y. Lee, W.S. Chang, Y.M. Yeon, S.B. Jung, Microstructural investigation of friction stir welded pure titanium. Mater. Lett., 59 (26) (2005), pp. 3315-3318

[4] N. Kahraman, B. Gulenc, F. Findik, Corrosion and mechanical-microstructural aspects of dissimilar joints of Ti6Al4V and Al plates. Int. J. Impact Eng., 34 (2007), pp. 1423-1432

[5] Z. Sun, I. Annergren, D. Pan, T.A. Mai, Effect of laser surface remelting on the corrosion behavior of commercially pure titanium sheet. Mater. Sci. Eng. A, 345 (1-2) (2003), pp. 293-300

[6] S.T. Auwal, S. Ramesh, F. Yusof, S.M. Manladan, A review on laser beam welding of titanium alloys. Int. J. Adv. Manuf. Technol., 971 (4) (2018), pp. 1071-1098

[7] M. Gao, C. Chen, L. Wang, Z. Wang, X. Zeng, Laser-Arc Hybrid Welding of Dissimilar Titanium Alloy and Stainless Steel Using Copper Wire. Mater. Trans. A, 46(5) (2015), pp. 2007-2020

[8] T. Wang, B. Zhang, J. Feng, and Q. Tang, Effect of a copper filler metal on the microstructure and mechanical properties of electron beam welded titanium-stainless steel join. Mater. Charact., 73 (2012), pp. 104-113

[9] R. Soltani Tashi, S.A.A. Akbari Mousavi, M. Mazar Atabaki, Diffusion brazing of Ti-6Al-4V and austeTiNic stainless steel using silver-based interlayer. Mater. Des., 54 (2014), pp. 161-167

[10] M.K. Lee, J.J. Park, J.G. Lee, and C. K. Rhee, Phase-dependent corrosion of titanium-to-stainless steel joints brazed by Ag-Cu eutectic alloy filler and Ag interlayer. J. Nucl. Mater., 439 (1-3) (2013), pp. 168-173

[11] A. Elrefaey, W. Tillmann, Correlation between microstructure, mechanical properties, and brazing temperature of steel to titanium joint. J. Alloys Compd., 487 (1-2) (2009), pp. 639-645.

[12] E. Norouzi, M. Atapour, M. Shamanian, A. Allafchian, Effect of bonding temperature on the microstructure and mechanical properties of Ti-6Al-4V to AISI 304 transient liquid phase bonded joint. Mater. Des., 99 (2016), pp. 543-551 
[13] S. Zakipour, A. Halvaee, A. A. Amadeh, M. Samavatian, A. Khodabandeh, An investigation on microstructure evolution and mechanical properties during transient liquid phase bonding of stainless steel $316 \mathrm{~L}$ to Ti-6Al-4V. J. Alloys Compd., 626 (2015), pp. 269-276

[14] V.Srikanth, A.Laik, G.K. Dey, Joining of stainless steel 304L with Zircaloy-4 by diffusion bonding technique using Ni and Ti interlayers. Mater. Des., 126 (2017), pp. 141-154.

[15] S. Kundu, S. Sam, S. Chatterjee, Interface microstructure and strength properties of Ti-6Al-4V and microduplex stainless steel diffusion bonded joints. Mater. Des., 32 (2011), pp. 2997-3003.

[16] M. Ghosh, S. Chatterjee, Diffusion bonded transition joints of titanium to stainless steel with improved properties. Mater. Sci. Eng. A, 358(1-2) (2003), pp. 152-158.

[17] D.H. Yang, Z.A. Luo, G.M. Xie, M.K. Wang, R. D. K. Misra, Effect of vacuum level on microstructure and mechanical properties of titanium-steel vacuum roll clad plates. J. Iron Steel Res. Int., 25 (1) (2018), pp. 72-80.

[18] H. R. Akramifard, H. Mirzadeh, M. H. Parsa, Cladding of aluminum on AISI 304L stainless steel by cold roll bonding: Mechanism, microstructure, and mechanical properties. Mater. Sci. Eng. A, 613 (2014), pp. 232-239.

[19] D. S. Zhao, J.C. Yan, Y.J. Liu, Heat resistance of hot roll bonded titanium alloy-stainless steel transition joint. Trans. Nonferrous Met. Soc. China, 23 (7) (2013), pp. 1966-1970.

[20] S. Kundu, S. Chatterjeelnterfacial microstructure and mechanical properties of diffusion-bonded titaniumstainless steel joints using a nickel interlayer. Mater. Sci. Eng. A, 425 (1-2) (2006), pp. 107-113.

[21] H. Arik, M. Aydin, A. Kurt, M. Turker, Weldability of Al4C3-Al composites via diffusion welding technique. Mater. Des., 26 (2005), pp. 555-560.

[22] M. Ghosh, K. Bhanumurthy, G.B. Kale, J. Krishnan, S. Chatterjee, Diffusion bonding of titanium to 304 stainless steel. J. Nucl. Mater., 322 (2-3) (2003), pp. 235-241

[23] M. Ghosh, S. Chatterjee, Diffusion bonded transition joints of titanium to stainless steel with improved properties. Mater. Sci. Eng. A, 358 (1-2) (2003), pp. 152-158

[24] Z. Yazdani, M.R. Toroghinejad, H. Edris, A.H.W. Ngan, A novel method for the fabrication of Al-matrix nanocomposites reinforced by mono-dispersed $\mathrm{TiAl}_{3}$ intermetallic via a three-step process of cold-roll bonding, heattreatment and accumulative roll bonding. J. Alloys Compd., 747 (2018), pp. 217-226

[25] M.M. Mahdavian, H. Khatami-Hamedani, H. R. Abedi, Macrostructure evolution and mechanical properties of accumulative roll bonded Al/Cu/Sn multilayer composite. J. Alloys Compd., 703 (2017), pp. 605-613

[26] H.G. Dong, Z.L. Yang, G.S. Yang, C. Dong, Vacuum brazing of TiAl alloy to 40Cr steel with Ti60Ni22Cu10Zr8 alloy foil as filler metal. Mater. Sci. Eng. A, 561 (2013), pp. 252-258.

[27] T.S. Lin, H.X. Li, P. He, H.M. Wei, L. Li, J.C. Feng, Microstructure evolution and mechanical properties of transient liquid phase (TLP) bonded joints of TiAl intermetallics. Intermetallics, 37 (2013), pp. 59-64

[28] T.F. Song, X.S. Jiang, Z.Y. Shao, Y.J. Fang, M.H. Zhu, Microstructure and mechanical properties of vacuum diffusion bonded joints between Ti-6Al-4V titanium alloy and AISI316L stainlesssteel using Cu/Nb multi- 
interlayer. Vacuum, 145 (2017), pp. 68-76

[29] M.Hosseini, H.Danesh Manesh, Bond strength optimization of Ti/Cu/Ti clad composites produced by rollbonding. Mater. Des., 81 (2015) , pp. 122-132

[30] M. Balasubramanian, Characterization of diffusion-bonded titanium alloy and 304 stainless steel with Ag as an interlayer. Int. J. Adv. Manuf. Technol., 82 (2016), pp. 153-162

[31] D.S. Zhao, J.C. Yan, C.W. Wang, Y. Wang, S.Q. Yang, Interfacial structure and mechanical properties of hot roll bonded joints between titanium alloy and stainless steel using copper interlayer. Sci. Technol. Weld. Joining, 13 (2008), pp. 765-768.

[32] J.C. Yan, D.S. Zhao, C.W. Wang, S.Q. Yang, Vacuum hot roll bonding of titanium alloy and stainless steel using nickel interlayer. J. Mater. Sci. Technol., 25 (2009), pp. 914-918

[33] S. Zakipour, A. Halvaee, A.A. Amadeh, M. Samavatian, A. Khodabandeh, An investigation on microstructure evolution and mechanical properties during transient liquid phase bonding of stainless steel $316 \mathrm{~L}$ toTi-6Al-4V. J. Alloys Compd. , 626 (2015), pp. 269-276

[34] M. Balasubramanian, Application of Box-Behnken design for fabrication of titanium alloy and 304 stainless steel joints with silver interlayer by diffusion bonding. Mater. Des., 77 (2015) , pp. 161-169

[35] Massalski TB. Binary alloy phase diagrams. 2nd ed. Materials Park(OH): ASM International; 1990.

[36] M. M. Verdian, K. Raeissi, M. Salehi, S. Sabooni, Characterization and corrosion behavior of $\mathrm{TiNi}^{-\mathrm{Ti}}{ }_{2} \mathrm{Ni}^{-} \mathrm{TiNi}_{3}$ multiphase intermetallics produced by vacuum sintering. Vacuum, 86 (2011), pp. 91-95.

[37] L.F. Hu,Y.Z. Xue, F.G. Shi, Intermetallic formation and mechanical properties of Ni-Ti diffusion couples. Mater. Des., 130 (2017), pp. 175-182.

[38] B. Feng, Y. Xin, R. Hong, H. Yu, Y. Wu, Q. Liu, The effect of architecture on the mechanical properties of Mg-3Al1Zn rods containing hard Al alloy cores. Scr. Mater., 98 (2015), pp. 56-59.

[39] X.B. Wang, J.V. Humbeeck, B. Verlinden, S. Kustov, Thermal cycling induced room temperature aging effect in Nirich TiNi shape memory alloy. Scr. Mater., 113 (2016), pp. 206-208

[40] Q.C. Fan, Y.H. Zhang, Y.Y. Wang, M.Y. Sun, Y.H. Wen, Influences of transformation behavior and precipitates on the deformation behavior of Ni-rich TiNi alloys. Mater. Sci. Eng. A, 700 (2017), pp. 269-280

[41] ASTM-D 1002-10 standards, ASTM, PA, 2010.

[42] ASTM-D 1876-01 standards, ASTM, PA, 2015.

[43] M. Verdier, I. Groma, L. Flandin, J.Lendavi, Y. Brechet, P. GuyotDislocation densities and stored energy after cold rolling of Al-Mg alloys: investigations by resistivity and differential scanning calorimetry. Scripta Mater., 37 (1997), 449-454.

[44] A.A. Shirzadi GhoshouniDiffusion Bonding Aluminium Alloys and Composites: New Approaches and Modeling (doctoral thesis) University of Cambridge (1998) 
[45] J.P. Oliveira, A.J. Cavaleiro, N. Schell, A. Stark, F.M. Braz Fernandes, Effects of laser processing on the transformation characteristics of TiNi: A contribute to additive manufacturing. Scr. Mater., 152 (2018), pp. 122-126.

[46] J.J. Marattukalam, V.K. Balla, M. Das, S. Bontha, S.K. Kalpathy, Effect of heat treatment on microstructure, corrosion, and shape memory characteristics of laser deposited TiNi alloy. J. Alloys Compd., 744 (2018), pp. 337346.

[47] J. Beres, A. Polar, J.E. Indacochea, Joining YSZ to 444 SS by in situ alloying in a N-Ti filler metal for SOFC applications; J.J. Stephens, K.S. Weil (Eds.), Proceeding of the 3rd international brazing and soldering conference, American Welding Society, San Antonio (2006), pp. 125-132.

[48] T.B. Massalski, H. Okamoto, P.R. Subramanian, L. KacprzakBinary. Alloy phase diagrams. (2nd ed.), ASM Intl, OH (1990)

[49] Y.Q. Deng, G.M. Sheng, C. Xu, Evaluation of the microstructure and mechanical properties of diffusion bonded joints of titanium to stainless steel with a pure silver interlayer. Mater. Des., 46 (2013), pp. 84-87.

[50] K. BataloviĆ, V. Kotesk, and D. StojiĆ. Hydrogen storage in martensite Ti-Zr-Ni alloy: A density functional theory study. J. Phys. Chem. C, 117(51) (2013), pp. 26914-26920.

[51] D. Toprek, J. Belosevic-cavor, and V. Koteski, Ab iTiNio studies of the structural, elastic, electronic and thermal properties of $\mathrm{TiNi}_{2}$ intermetallic. J. Phys. Chem. Solids, 85 (2015), pp. 197-205.

[52] Q. Chen, Z. Huang, Z. Zhao, and C. Hu, First-principles study on the structural, elastic, and thermodynamics properties of Ni3X (X: Al, Mo, Ti, Pt, Si, Nb, V, and Zr) intermetallic compounds. Appl. Phys. A, 116(3) (2013), pp. 1-12.

[53] B. Li, L. Rong, Y. Li, V.E. GjunterFabrication of cellular TiNi intermetallic compounds. J. Mater. Res., 15 (1) (2000), pp. 10-13

[54] L. Battezzati, P. Pappalepore, F. Durbiano, I. Gallino, Solid state reactions in Al/Ni alternate foils induced by cold rolling and annealing. Acta Mater., 47 (6) (1999), pp. 1901-1914.

[55] X. Shao, X.L. Guo, Y.F. Han, Z.J. Lin, J. Qin, W.J. Lu, D. Zhang, Preparation of TiNi films by diffusion technology and the study of the formation sequence of the intermetallics in Ti-Ni system, J. Mater. Res., 29 (22) (2017), 27072716.

[56] Y. Zhang, X. Cheng, H. Cai, Fabrication, characterization and tensile property of a novel Ti2Ni/TiNi microlaminated composite, Mater. Des. 92 (2016), 486-493.

[57] E.A. Brandes (ed.), Smithells Metals Reference Book, Butterworth, London, 1983.

[58] K. Otsuka, X. RenPhysical metallurgy of Ti-Ni-based shape memory alloys Prog. Mater Sci., 50 (2005), pp. 511678

[59] D.L. Ye, J.H. HuUtility Inorganic Materials Thermodynamics Data Handbook (second ed.), Metallurgy Industry Press, Beijing (2002)

[60] P. Villars, A. Prince, H. Okamoto, Hand book of Ternary Phase Alloys, vol. 7, ASM Int., Mater. Park, Ohio (1995) pp. 8903-8928. 
[61] T. B. Massalski (ed.), Binary Phase Diagrams, American Society for Metals, Metals Park, OH, 1986.

[62] V. Raghavan,, J. Phase Equilb. Diff., 31 (2010), pp. 186-189.

[63] N. Orhan, T.I. Khan, M. Eroglu, Diffusion Bonding of a Microduplex Stainless Steel to Ti-6Al-4V, 45 (2001), pp. 441446.

[64] Y. Ma, H. Li, L. Yang, A. Hu, Reaction-assisted diffusion bonding of Ti6Al4V alloys with Ti/Ni nanostructured multilayers. J. Mater. Sci. Technol., 262 (2018), pp. 204-209.

[65] C.H. Muralimohan, M. Ashfaq, R. Ashiri, V. Muthupandi, K. Sivaprasad, Analysis and Characterization of the Role of Ni Interlayer in the Friction Welding of Titanium and 304 AusteTiNic Stainless Steel. Mater. Trans. A, 47 (2016), pp. 347-359.

[66] A. Yıldız, Y. Kaya, N. Kahraman, Joint properties and microstructure of diffusion-bonded grade 2 titanium to AISI 430 ferritic stainless steel using pure Ni interlayer. Int. J. Adv. Manuf. Technol., 86 (2016), pp. 1287-1298.

[67] J. Liu, J. Cao, X. Song, Y. Wang, J. Feng, Evaluation on diffusion bonded joints of TiAl alloy to Ti3SiC2 ceramic with and without Ni interlayer: Interfacial microstructure and mechanical properties. Mater. Des., 57 (2014) , pp. 592597.

[68] Y.Q. Deng, G.M. Sheng, C. Xu, Evaluation of the microstructure and mechanical properties of diffusion bonded joints of titanium to stainless steel with a pure silver interlayer. Mater. Des., 46 (2013), pp. 84-87.

[69] S. Hinotani, Y. Ohmori, The Microstructure of Diffusion-bonded Ti/Ni Interface. Trans. Jpn. Inst. Mater., 29 (1988), pp. 116-124.

[70] Benedictus, R., Böttger, A., and Mittemeijer, E.: Thermodynamic model for solid-state amorphization in binary systems at interfaces and grain boundaries. Phys. Rev. B 54(13), 9109 (1996).

[71] Li, Y., Cui, L., Shi, P., and Yang, D.: Phase transformation behaviors of prestrained TiNi shape memory alloy fibers under the constraint of a hard substrate. Mater. Lett. 49(3), 224 (2001).

[72] De Boer, F., Boom, R., Mattens, W., Miedema, A., and Niessen, A.: Cohesion in Metals. Transition Metal Alloys: Cohesion and Structure (North-Holland, Amsterdam, 1989); Chap. 2.

[73] A. Miedema, P. De Chatel, and F. De Boer: Cohesion in alloys-fundamentals of a semi-empirical model. Physica B 1 C 100(1), 1 (1980).

[74] A. Miedema: On the heat of formation of solid alloys. II. J. Less-Common Met. 46(1), 67 (1976).

[75] J. Liu, Y. Su, Y. Xu, L. Luo, J. Guo, and H. Fu: First phase selection in solid Ti/Al diffusion couple. Rare Met. Mater. Eng. 40(5), 753 (2011)

[76] S. Kundu, S. Chatterjee, Structure and properties of diffusion bonded transition joints between commercially pure titanium and type 304 stainless steel using a nickel interlayer. J. Mater. Sci., 42 (2007), pp. 7906-7912.

[77] S. Kundu, S. Chatterjee, D. Olson, B. Mishra, Effects of intermetallic phases on the bond strength of diffusionbonded joints between titanium and 304 stainless steel using nickel interlayer. Mater. Trans. A, 38 (2007), pp. 20532060. 


\section{Figures}

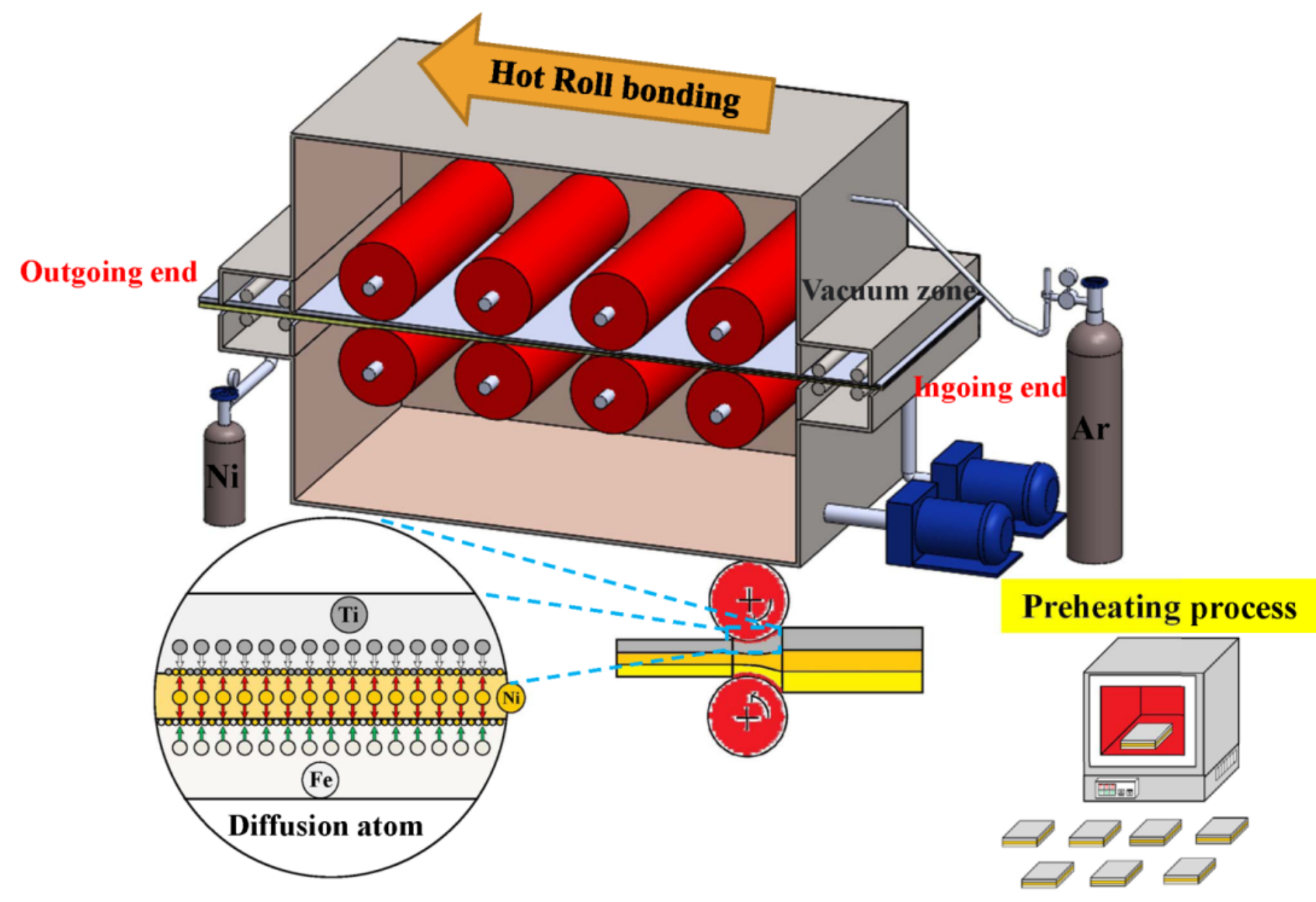

Figure 1

Schematic illustration showing structure of hot-roll diffusion-bonded joints. 
(a)

(b)
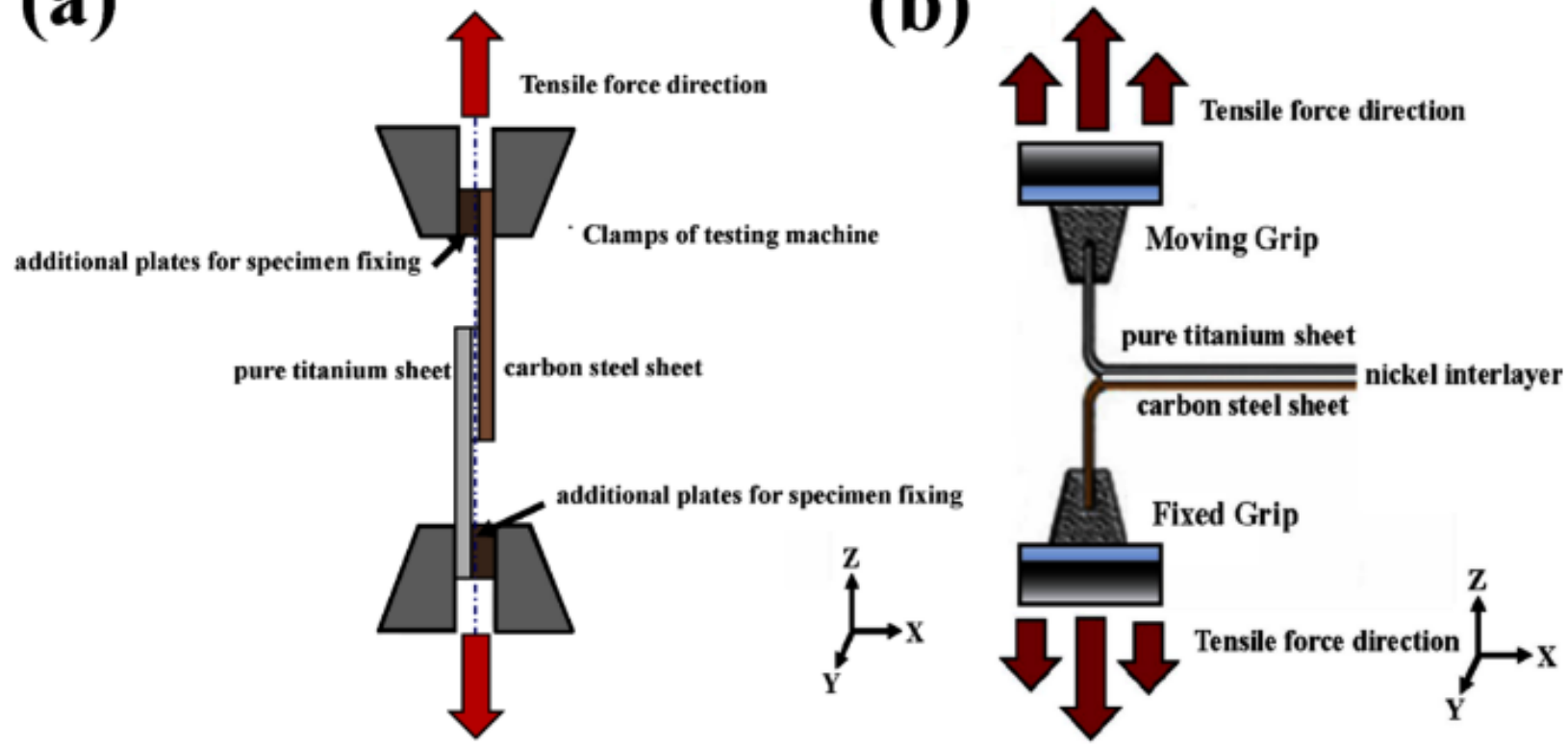

Figure 2

Schematic illustration showing (a) shear strength tests and (b) peel strength tests of hot-roll diffusion-bonded joints.

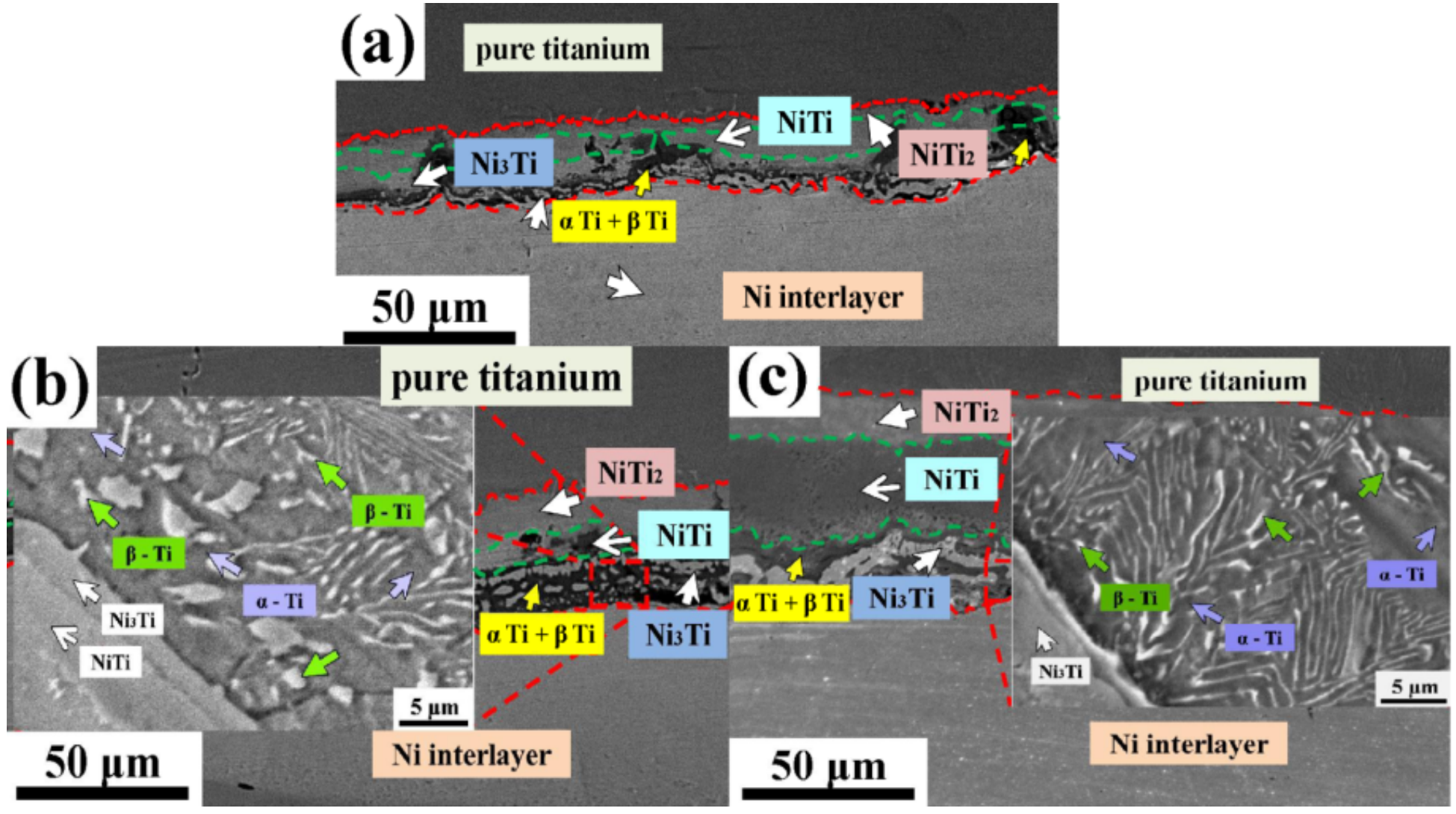

Figure 3

Backscattered electron (BE) images of cross-sectional regions of pure Ti and carbon steel hot-roll diffusion-bonded joints with $\mathrm{Ni}$ interlayer processed at temperatures of (a) $800^{\circ} \mathrm{C}$, (b) $850^{\circ} \mathrm{C}$, and (c) $900^{\circ} \mathrm{C}$. 


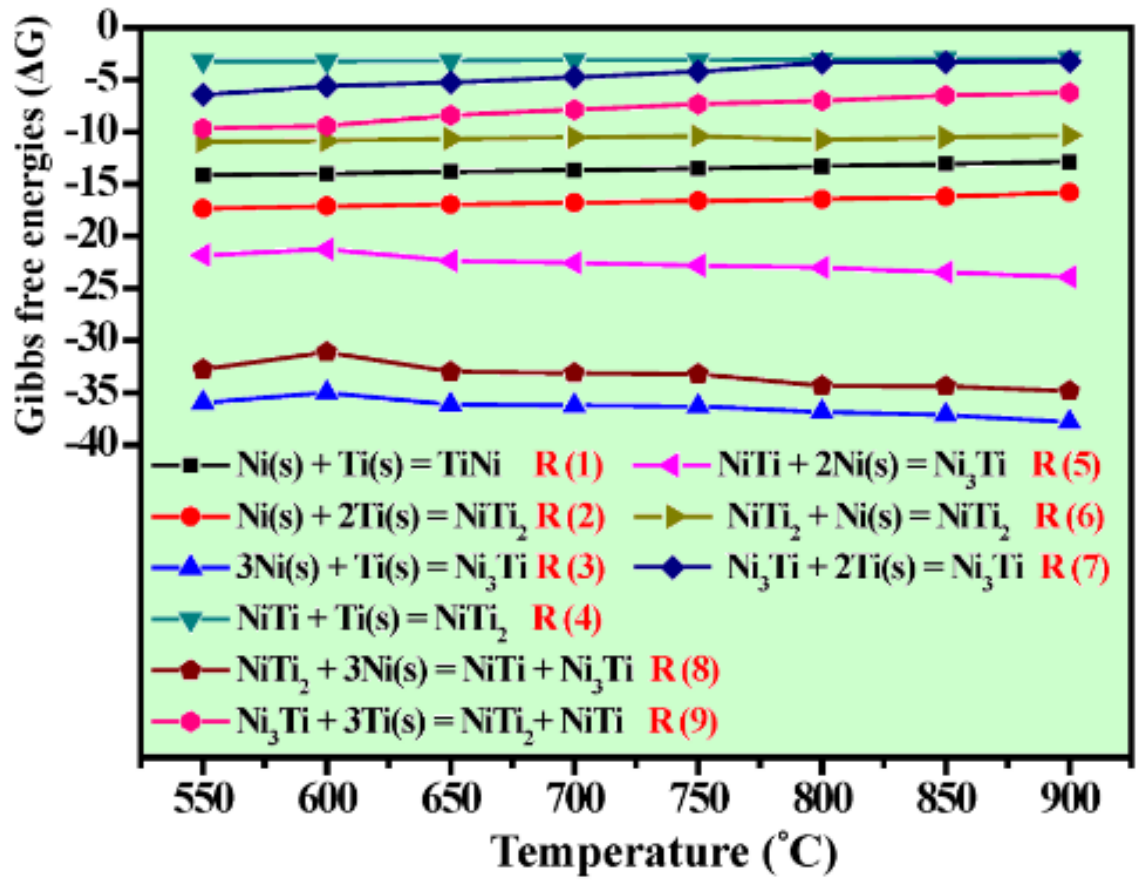

Figure 4

Gibbs free energy curve for each reaction at Ti-Ni diffusion interface as a function of temperature [54].

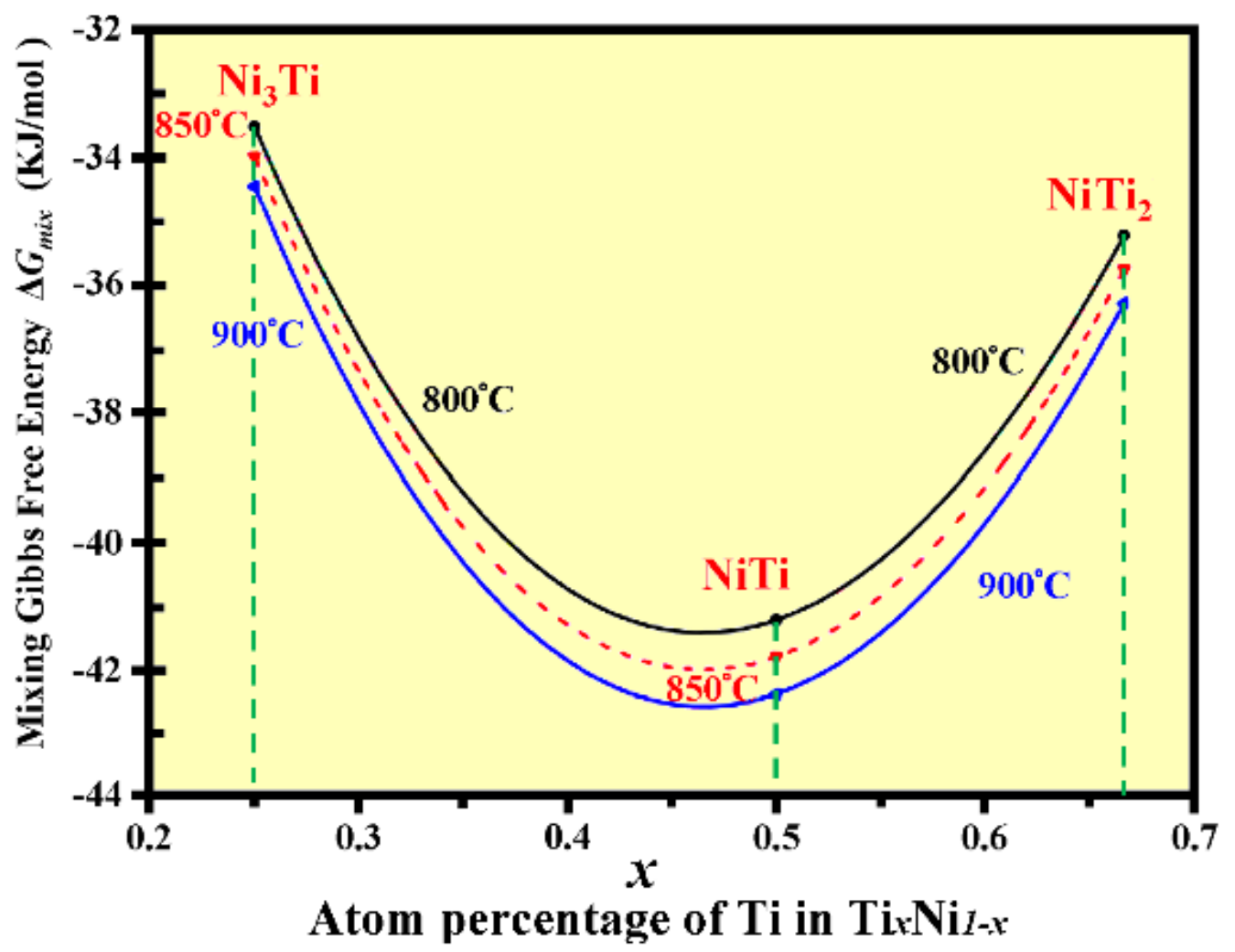

Figure 5

Gibbs free energy of mixing associated with formation of various solid solutions and compounds at Ti-Ni diffusion interface. 


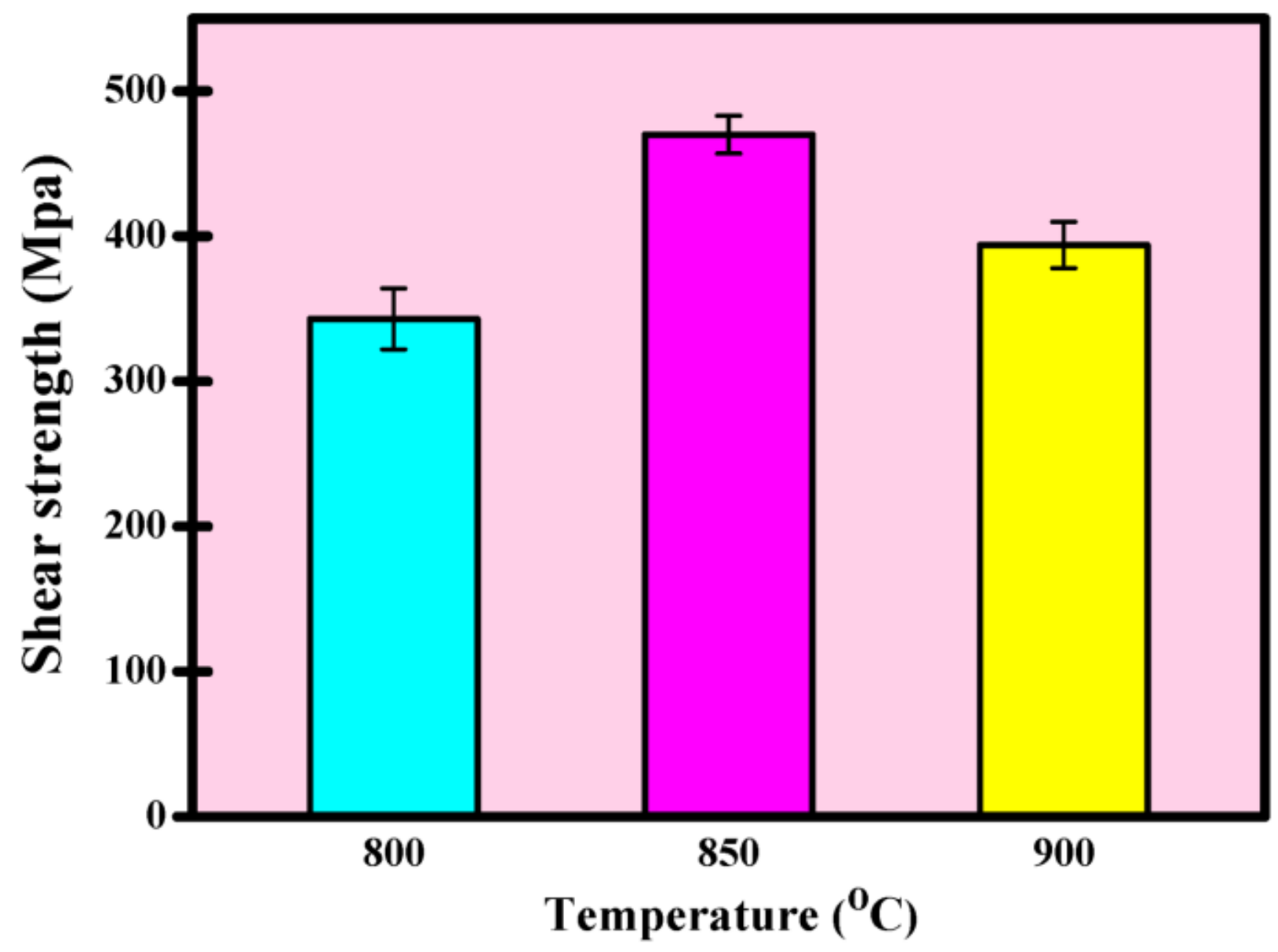

Figure 6

Interfacial shear strengths of $\mathrm{Ti}$ and carbon steel hot-roll diffusion-bonded joints with Ni interlayer processed at temperatures of $800^{\circ} \mathrm{C}, 850^{\circ} \mathrm{C}$ and $900^{\circ} \mathrm{C}$.
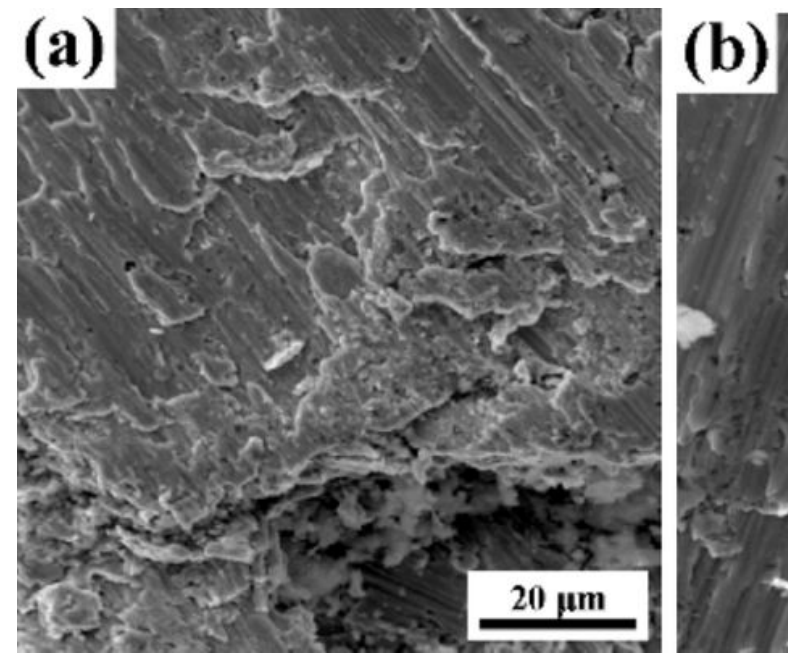

(c)

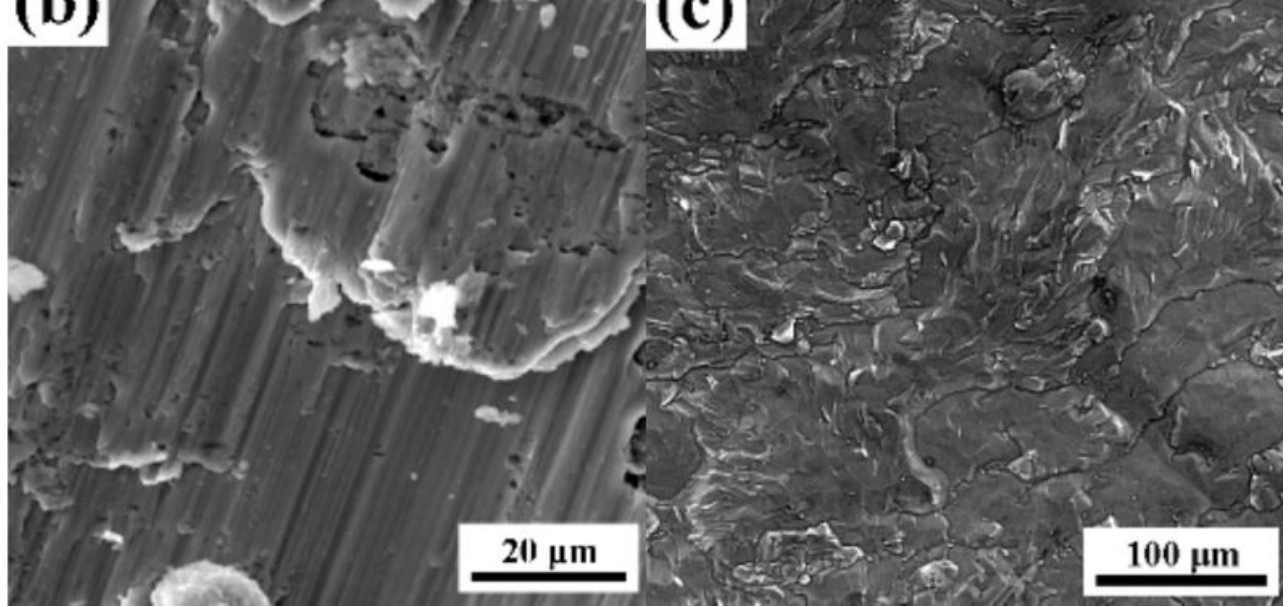

Figure 7

SEM fractographs (Ti side) of Ti and carbon steel hot-roll diffusion-bonded joints with Ni interlayer processed at temperatures of (a) $800^{\circ} \mathrm{C}$, (b) $850^{\circ} \mathrm{C}$, and (c) $900^{\circ} \mathrm{C}$. 


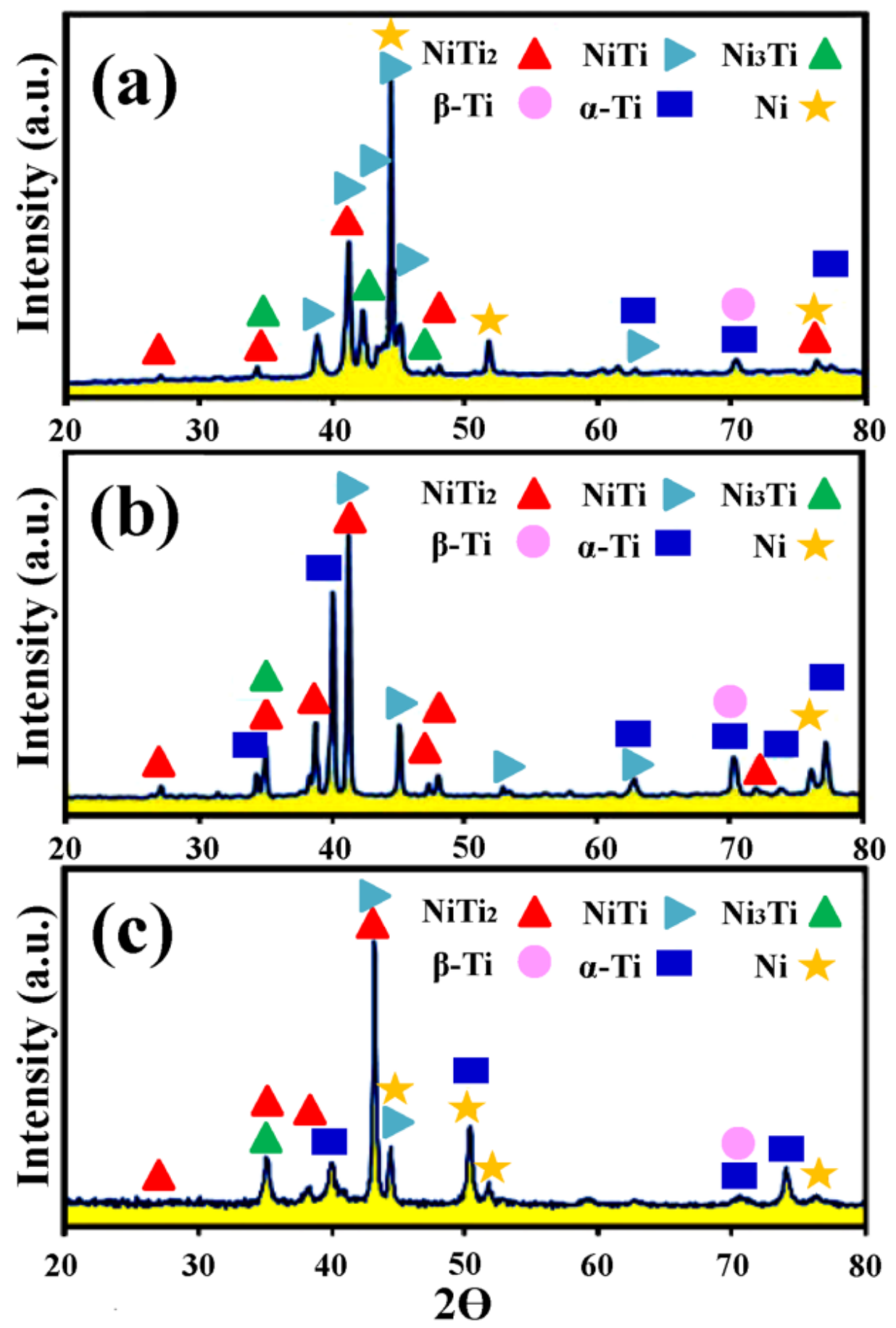

Figure 8

XRD patterns of fracture surface of $\mathrm{Ti}$ and carbon steel hot-roll diffusion-bonded joints with Ni interlay er processed at temperatures of (a) $800^{\circ} \mathrm{C}$, (b) $850^{\circ} \mathrm{C}$, and (c) $900^{\circ} \mathrm{C}$. 

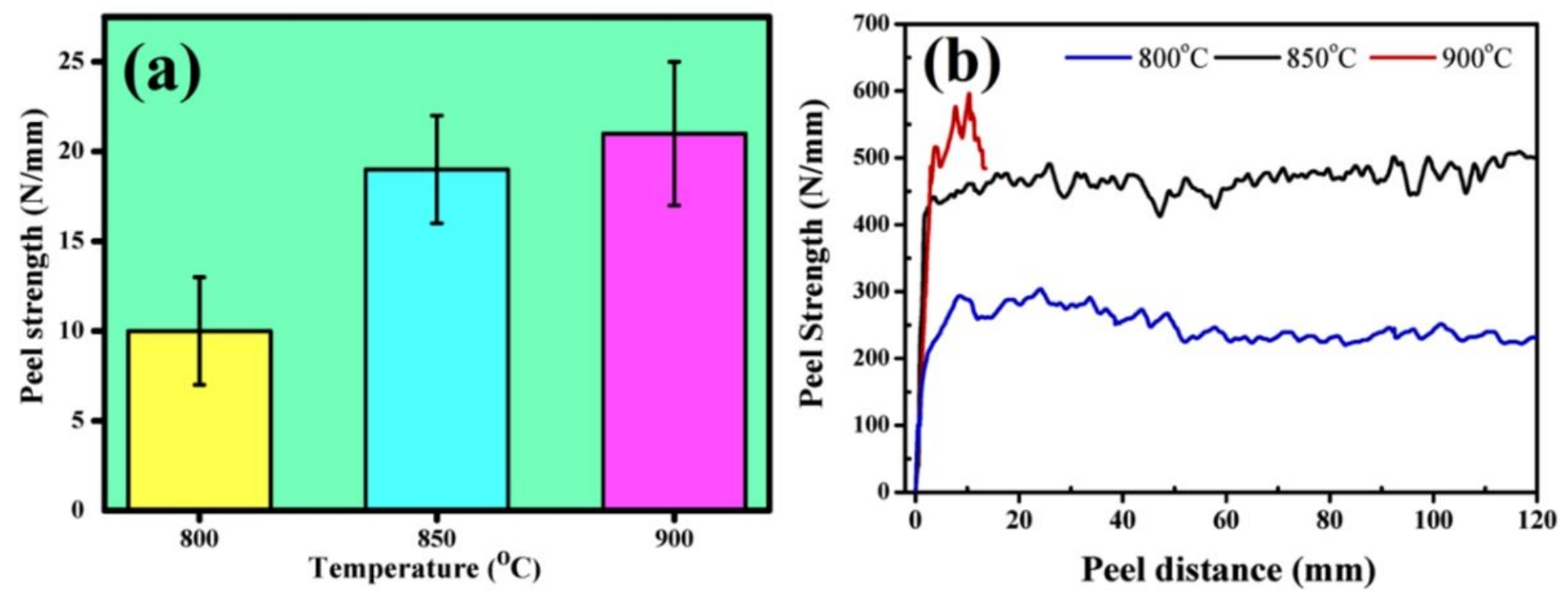

Figure 9

Interfacial bonding strength of $\mathrm{Ti}$ and carbon steel hot-roll diffusion-bonded joints with $\mathrm{Ni}$ interlayer: (a) average interfacial bonding strength, and (b) interfacial bonding strength as function of peeling displacement. 